\title{
Erythropoietin stimulates fibroblast growth factor 23 (FGF23) in mice and men
}

\author{
Daryadel, Arezoo ; Bettoni, Carla ; Haider, Thomas ; Imenez Silva, Pedro H ; Schnitzbauer, Udo ;
} Pastor-Arroyo, Eva Maria ; Wenger, Roland H ; Gassmann, Max ; Wagner, Carsten A

\begin{abstract}
Fibroblast growth factor 23 (FGF23) is a major endocrine regulator of phosphate and 1,25 $(\mathrm{OH}) 2$ vitamin D3 metabolism and is mainly produced by osteocytes. Its production is upregulated by a variety of factors including 1,25 (OH)2 vitamin D3, high dietary phosphate intake, and parathyroid hormone $(\mathrm{PTH})$. Recently, iron deficiency and hypoxia have been suggested as additional regulators of FGF23 and a role of erythropoietin (EPO) was shown. However, the regulation of FGF23 by EPO and the impact on phosphate and 1,25(OH)2 vitamin D3 are not completely understood. Here, we demonstrate that acute administration of recombinant human EPO (rhEPO) to healthy humans increases the Cterminal fragment of FGF23 (C-terminal FGF23) but not intact FGF23 (iFGF23). In mice, rhEPO stimulates acutely $(24 \mathrm{~h})$ C-terminal FGF23 but iFGF23 only after 4 days without effects on PTH and plasma phosphate. 1,25 (OH)2 D3 levels and klotho expression in the kidney decrease after 4 days. rhEPO induced FGF23 mRNA in bone marrow but not in bone, with increased staining of FGF23 in CD71+ erythroid precursors in bone marrow. Chronic elevation of EPO in transgenic mice increases iFGF23. Finally, acute injections of recombinant FGF23 reduced renal EPO mRNA expression. Our data demonstrate stimulation of FGF23 levels in mice which impacts mostly on 1,25 (OH)2 vitamin D3 levels and metabolism. In humans, EPO is mostly associated with the C-terminal fragment of FGF23; in mice, EPO has a time-dependent effect on both FGF23 forms. EPO and FGF23 may form a feedback loop controlling and linking erythropoiesis and mineral metabolism.
\end{abstract}

DOI: https://doi.org/10.1007/s00424-018-2171-7

Posted at the Zurich Open Repository and Archive, University of Zurich

ZORA URL: https://doi.org/10.5167/uzh-152331

Journal Article

Accepted Version

Originally published at:

Daryadel, Arezoo; Bettoni, Carla; Haider, Thomas; Imenez Silva, Pedro H; Schnitzbauer, Udo; PastorArroyo, Eva Maria; Wenger, Roland H; Gassmann, Max; Wagner, Carsten A (2018). Erythropoietin stimulates fibroblast growth factor 23 (FGF23) in mice and men. Pflügers Archiv : European Journal of Physiology, 470(10):1569-1582.

DOI: https://doi.org/10.1007/s00424-018-2171-7 


\title{
Erythropoietin stimulates Fibroblast Growth Factor 23 (FGF23) in mice and men
}

\author{
Arezoo Daryadel ${ }^{1,2}$, Carla Bettoni ${ }^{1,2,}$ Thomas Haider ${ }^{3,4}$, Pedro H. Imenez Silva ${ }^{1,2}$, \\ Udo Schnitzbauer ${ }^{1,2}$, Eva Maria Pastor-Arroyo ${ }^{1,2}$, Roland H. Wenger ${ }^{1,2,4}$, \\ Max Gassmann ${ }^{3,4}$, Carsten A. Wagner ${ }^{1,2,4}$ \\ ${ }^{1}$ Institute of Physiology, University of Zurich, Zurich, Switzerland \\ ${ }^{2}$ National Center of Competence in Research NCCR Kidney.CH, Switzerland \\ ${ }^{3}$ Institute of Veterinary Physiology, Vetsuisse Faculty, University of Zurich, \\ Switzerland \\ ${ }^{4}$ Zurich Center for Integrative Human Physiology (ZIHP), University of Zurich, \\ Switzerland
}

Correspondence to:

Carsten A. Wagner

Institute of Physiology

University of Zurich

Winterthurerstrasse 190

$\mathrm{CH}-8057$ Zurich

Switzerland

Email: Wagnerca@access.uzh.ch

Phone: +41-44-63 55023

Fax: +41-44-63 56814 


\section{ABSTRACT}

Fibroblast growth factor 23 (FGF23) is a major endocrine regulator of phosphate and 1,25 $(\mathrm{OH})_{2}$ vitamin $\mathrm{D}_{3}$ metabolism and is mainly produced by osteocytes. Its production is up-regulated by a variety of factors including $1,25(\mathrm{OH})_{2}$ vitamin $\mathrm{D}_{3}$, high dietary phosphate intake, and parathyroid hormone (PTH). Recently, iron deficiency and hypoxia have been suggested as additional regulators of FGF23 and a role of erythropoietin (EPO) was shown. However, the regulation of FGF23 by EPO and the impact on phosphate and $1,25(\mathrm{OH})_{2}$ vitamin $\mathrm{D}_{3}$ are not completely understood. Here, we demonstrate that acute administration of recombinant human EPO (rhEPO) to healthy humans increases the C-terminal fragment of FGF23 (Cterminal FGF23) but not intact FGF23 (iFGF23). In mice, rhEPO stimulates acutely (24 hrs) C-terminal FGF23 but iFGF23 only after 4 days without effects on PTH and plasma phosphate. 1,25 $(\mathrm{OH})_{2} \mathrm{D}_{3}$ levels and aklotho expression in kidney decrease after 4 days. rhEPO induced FGF23 mRNA in bone marrow but not in bone, with increased staining of FGF23 in CD71+ erythroid precursors in bone marrow. Chronic elevation of EPO in transgenic mice increases iFGF23. Finally, acute injections of recombinant FGF23 reduced renal EPO mRNA expression. Our data demonstrate stimulation of FGF23 levels in mice which impacts mostly on $1,25(\mathrm{OH})_{2}$ vitamin $\mathrm{D}_{3}$ levels and metabolism. In humans, EPO is mostly associated with the C-terminal fragment of FGF23, in mice EPO has a time-dependent effect on both FGF23 forms. EPO and FGF23 may form a feedback loop controlling and linking erythropoiesis and mineral metabolism.

Key Words: Mineral metabolism, Erythropoietin, FGF23, Vitamin D3, kidney, bone 


\section{INTRODUCTION}

Fibroblast growth factor 23 (FGF23) is an osteocyte-derived hormone that increases renal phosphate excretion by decreasing the expression of the renal phosphate cotransporters NaPilla and NaPllc expressed in the renal proximal tubule [17]. FGF23 also reduces the levels of circulating active $1,25(\mathrm{OH})_{2}$ vitamin $\mathrm{D}_{3}$ through stimulating its degradation by cytochrome P450 (CYP) 24A1 and decreasing its synthesis by CYP27B1 [17]. These classic functions of FGF23 require aklotho as an obligatory co-ligand/co-receptor mostly at the FGF1c receptor $[3,17]$. aKlotho is predominantly expressed in the kidney and its abundance appears to be stimulated by an FGF23-dependent mechanism [20,30]. Additional effects of FGF23 are emerging which only partly depend on aklotho such as a role of FGF23 in inducing left ventricular hypertrophy [17]. Also, a role of FGF23 in inhibiting early steps of erythropoiesis has been reported [7].

FGF23 levels are regulated by a variety of stimuli and factors that can induce circulating levels of intact biologically active FGF23 and may also act on the levels of the C-terminal fragment (C-term.) of FGF23 [17]. C-term. FGF23 originates from cleaving intact FGF23 (iFGF23) and is thought to mainly represent an inactive degradation product [17]. However, C-terminal FGF23 may still bind to the FGF1c receptor without activating it but protecting the receptor from activation by full-length iFGF23 [14]. Thus, the ratio between intact and C-term. FGF23 may modulate the biological activity of the system. Stimuli that increase FGF23 are parathyroid hormone, 1,25 $(\mathrm{OH})_{2}$ vitamin $\mathrm{D}_{3}$, aldosterone, phosphate loading and also include iron deficiency and inflammatory stimuli $[18,11,6,35,36]$. Iron deficiency and anemia have been recently associated with FGF23 levels, particularly in patients with chronic 
kidney disease $[25,33]$. Very recently, erythropoietin (EPO) has been identified as a potential link between anemia, iron status and FGF23, and as a stimulus for FGF23 production $[5,12,26]$. EPO has been suggested to cause at least in part the rapid surge in FGF23 in patients and animal models with acute kidney injury (AKI) [31] and blockade of FGF23 signalling has been recently suggested for treatment of renal anemia of CKD [1]. We thus examined the association between EPO and FGF23 in healthy young volunteers and in mice, and report that EPO increases C-term. FGF23 but not iFGF23 in healthy human volunteers. In mice, EPO elevates first C-term. FGF23 and then iFGF23. iFGF23 in turn reduces renal EPO mRNA expression, suggesting that EPO and FGF23 form a feedback loop. 


\section{MATERIALS AND METHODS}

\section{Experimental animals}

C57BL/6 male mice (8-12 weeks, 25-30 g) were obtained from Janvier, France. For some experiments, transgenic mice overexpressing human EPO (EPO-Tg6 mice) were used [28]. All animal experiments were performed in accordance with Swiss and international laws of animal protection and welfare and all protocols were approved by the appropriate local veterinary authority (Kantonales Veterinäramt Zürich).

Treatment with recombinant human erythropoietin, recombinant FGF23, PHD inhibitor, or diets with different phosphate content

C57BL/6mice were injected intraperitoneally either once or daily for 4 consecutive days with saline or $2000 \mathrm{IU} / \mathrm{kg}$ recombinant human erythropoietin (rhEPO) Epoetin alfa, Eprex, Janssen) [13] or a single injection of recombinant human iFGF23 (rhFGF23, $10 \mu \mathrm{g}$ per mice) (AdipoGen; AG-40A-0128). Blood plasma and kidneys were collected at $30 \mathrm{~min}$. and 24 hours. Roxadustat (FG-4592, Sigma Aldrich, Buchs, Switzerland) was injected intraperitoneally with a dose of $50 \mathrm{mg} / \mathrm{kg} /$ day for 4 days [34], the control groups received a similar volume of vehicle (5\% DMSO-50\% polyethylenglycol in water) solution. Animals receiving rhEPO or vehicle were sacrificed 24 hrs or 4 days after the initial injection. Animals receiving roxadustat or vehicle were sacrificed 4 days after the initial injection. In one series of experiments mice received diets with low $(0.1 \% \mathrm{Pi})$ or high $(1.2 \% \mathrm{Pi})$ phosphate content. All other dietary components (i.e. calcium, vitamin $\mathrm{D}_{3}$, iron) were kept constant. All diets were from Kliba Nafag AG (Kaiseraugst, Switzerland). Heparinized blood was collected 
from the heart and rapidly centrifuged at $4^{\circ} \mathrm{C}$ to collect plasma. Tibias, liver and kidneys were collected, rapidly frozen in liquid nitrogen and stored at $-80^{\circ} \mathrm{C}$ until analysis.

\section{Human study}

The present study was part of the 'EPOPERF-Project', a randomized double-blinded, placebo-controlled, crossover clinical trial (https://clinicaltrials.gov, identifier code: NCT01889056) to test whether a single high dose of erythropoietin (rhEPO) can modulate cognition and exercise performance in healthy humans (primary study outcome). Briefly, venous blood samples (from an arm vein) were collected from 32 healthy subjects (13 females, mean age: 24.9 years, age range: 21.0 - 31.0 years, 19 males, mean age: 24.4 years, age range: 21.1 - 32.0 years) in citrate coated tubes (BD Vacutainer $2.7 \mathrm{ml}$, Plymouth, UK) 24 hours post treatment with a single high dose of rhEPO (short infusion of 60.000 I.U. per person of Recormon $\AA$, recombinant human erythropoietin beta, Roche, Switzerland diluted into $250 \mathrm{ml}$ of $0.9 \%$ saline solution) and Placebo (short infusion of $250 \mathrm{ml}$ of $0.9 \%$ saline solution) in a crossover fashion (washout period between the two different treatments $\geq 4$ weeks). All blood samples of the present study were collected at baseline prior to any further study interventions. After the collection the blood samples were centrifuged at $1000 \mathrm{x}$ $\mathrm{g}$ for 10 minutes, the cell free supernatant (blood plasma) was transferred into new $1.5 \mathrm{ml}$ aliquot tubes and kept at $-80^{\circ} \mathrm{C}$ for further analysis. Of note, the plasma samples of 4 subjects were not available for this time point and were therefore not measured $(n=28)$. The main inclusion criteria of the trial were: males and females (age range: 18 to 35 years), healthy and normal weighted (body mass index, BMI $\geq$ $18.5 \mathrm{~kg} / \mathrm{m}^{2} \leq 24.9 \mathrm{~kg} / \mathrm{m}^{2}$ ), non-smokers ( $\geq 1$ year), maximal oxygen uptake, VO2max 
males $\leq 60 \mathrm{ml} / \mathrm{kg} / \mathrm{min}$, females $\leq 55 \mathrm{ml} / \mathrm{kg} / \mathrm{min}$ ) and the main exclusion criteria were: abnormal serum ferritin levels (range, males: $30-400 \mu \mathrm{g} / \mathrm{L}$, females: $13-150 \mu \mathrm{g} / \mathrm{L}$ ), genetic predisposition for frequent haemostatic disorders (factor $\mathrm{V}$ Leiden mutation R506Q, prothrombin mutation G20210A), history of deep venous thrombosis, haematocrit level $\geq 55 \%$, high-altitude exposure ( $\geq 2500 \mathrm{~m}$ asl) for $\geq 5$ consecutive days within the last 6 months prior to the study, and in females: pregnancy, breast feeding.

\section{Bone marrow cell preparation}

Bone marrow cells were obtained by rinsing each tibia of WT mice with $1 \mathrm{ml}$ of PBS using a 26-gauge needle. Cells were fixed on glass slides by cytospin centrifugation and stained as described previously for similar preparations [10].

\section{Biochemical analyses}

Plasma biochemical parameters were analyzed using a UniCel® SYNCHRON® DxC 800 Synchron Clinical System (Beckman Coulter), a service provided by the Zürich Integrative Rodent Physiology (ZIRP) facility. Plasma hematocrit was measured in capillaries whose walls were coated with heparin. After filling the capillary, capillaries were centrifuged in a special centrifuge (Haematokrit 210, Hettich Zentrifugen; Huber \& co. AG, Reinach, Switzerland) at $8000 \mathrm{rpm}$ for 5 minutes.

\section{FGF23, PTH and vitamin D measurements}


Plasma levels of mouse/rat iFGF23 (Immutopics; 60-6800), mouse/rat C-term. FGF23 (Immutopics; 60-6300), human iFGF23 (Immutopics; 60-6600), human Cterm FGF23 (Immutopics; 60-6100) and mouse PTH 1-84 (Immutopics; 60-2305) were measured by ELISA. Plasma 1,25-(OH)2-Vitamin $\mathrm{D}_{3}$ was determined by a radioimmunoassay (Immunodiagnostic System, Frankfurt am Main, Germany).

\section{Quantitative real-time reverse transcription PCR}

Mice kidney, liver, tibia and bone marrow cells were homogenized in QIAzol lysis reagent (Qiagen) and followed by chloroform (Sigma-Aldrich) extraction. RNA from QIAzol-chloroform extractions was isolated using the Qiagen RNeasy Mini kit (Qiagen, Hombrechtikon, Switzerland) following the protocol provided by the supplier. After RNA quantification using a Nanodrop ND-1000 spectrophotometer (Thermo Scientific), reverse transcription was carried out using the Taqman Reverse Transcription Kit (Applied Biosystems, Zug, Switzerland) according to the manufacturer's protocol. To quantify mRNA levels, specific sets of primers and probes for mouse FGF23, hepcidin, Cyp24a1, Cyp27b1, VDR, Galnt3, Phex, and Runx2 (supplementary table 1) were designed using Primer Express (Applied Biosystems) and purchased from Microsynth, (Switzerland). The specificity of all primers was tested using adult mouse kidney, liver and bone cDNA by conventional PCR. Each pair of primer resulted only in a single band of the expected size (data not shown). The probes were labelled with the reporter dye FAM at the $5^{\prime}$ end and the quencher dye TAMRA at the $3^{\prime}$ end. The complementary DNA (cDNA) was amplified using mouse primers listed in supplementary table 1 in RT-PCR reactions using the KAPA PROBE FAST qPCR Kit Master Mix (KAPA BIOSYSTEMS, Boston USA) containing primers $(5 \mu \mathrm{M})$ and probe $(25 \mu \mathrm{M})$ to amplify cDNA in a 7500 Fast Real 
Time PCR System (Applied Biosystems, Zug, Switzerland). For quantification of renal EPO mRNA expression, real-time PCR was performed using KAPA SYBER FAST qPCR Master Mix (KAPA BIOSYSTEMS, Boston USA). EPO primer sequences were described before [19] and are listed in supplementary table 1. Each reaction was done in triplicates and the average taken. Samples without enzyme in the RT reaction were used as negative controls to exclude contamination with genomic DNA. The cycle number at a given threshold (Ct) was measured. The expression of FGF23, hepcidin, Cyp27b1, Cyp24a1, VDR, Galnt3, Phex and Runx2 transcripts were normalized to the reference gene HPRT, when giving comparable results, and calculated by the formula $R=2^{\wedge}$ (CtHPRT - Ctgene of interest).

\section{Immunohistochemistry}

Freshly isolated bone marrow cells of tibia of C57BL/J mice either injected with saline or EPO $(2000 \mathrm{IU} / \mathrm{kg} /$ daily $)$ for 4 days were fixed with $4 \%$ paraformaldehyde/phosphate-buffered saline, $\mathrm{pH} 7.4$ [PBS] at room temperature for 10 min and washed with PBS, pH 7.4. Permeabilization of cells was performed with $0.05 \%$ saponin in $\mathrm{PBS} \mathrm{pH} 7.4$, for $5 \mathrm{~min}$ at room temperature. To prevent nonspecific binding, slides were incubated in blocking buffer (containing $10 \%$ normal donkey serum and 7.5\% bovine serum albumin, in PBS) at room temperature for 1 hour [10]. Indirect immunofluorescence staining was performed by using polyclonal goat anti mouse FGF23 antibody (1:20, Immutopics; 40-6810), monoclonal rat anti mouse CD71 (8D3) (1:50, Novus Biologicals; NB100-64979), monoclonal rat anti mouse CD68 (FA-11) (1:50, Bio-Rad; MCA1957GA), monoclonal PE/Dazzle ${ }^{T M} 594$ antimouse CD11C (N418) (1:50, Biolegend; 117348) and monoclonal rat anti mouse CD115 (c-fms) (1:50, Invitrogen; AFS98). After overnight incubation with primary 
antibodies at $4^{\circ} \mathrm{C}$, slides were washed with PBS and further incubated with Alexa fluor-488-conjugated donkey anti-goat (1:500; Life Technologies) or Alexa fluor-647conjugated donkey anti-rat (1:500, Life Technologies) antibodies in the dark at room temperature for 1 hour. Nuclei were stained with 2',6-diamidino-2-phenylindole dihydrochloride (DAPI) (1 mg/ml; 1:500, Sigma, D9542). Thereafter, slides were washed three times with PBS and covered by mounting medium (DAKO, USA) and coverslips. Pictures were taken with a Lecia DM5500B epifluorescence microscope and processed (overlays) using Adobe Photoshop (Adobe Photoshop, San Jose, CA). The Images in the figures are representatives of data obtained from four saline and rhEPO injected mice.

\section{Protein extractions and Western blotting}

As previously described [9], mouse kidneys were homogenized in ice-cold membrane extraction buffer (200 mM mannitol, $80 \mathrm{mM}$ HEPES, $41 \mathrm{mM} \mathrm{KOH}, \mathrm{pH}$ 7.5) supplemented with protease inhibitor cocktail (Complete; Roche Diagnostics, Basel, Switzerland). The homogenate was centrifuged at $2,000 \mathrm{rpm}$ for $20 \mathrm{~min}$ at $4^{\circ} \mathrm{C}$. The resulting supernatant was further centrifuged at $41,000 \mathrm{rpm}$ for 1 hour at $4^{\circ} \mathrm{C}$ and the pellet resuspended in the membrane extraction buffer. Total protein content was measured using the Bio-Rad Dc protein Assay (Bio-Rad, Hercules, CA, USA). Fifty $\mu \mathrm{g}$ of membrane protein were solubilised in Laemmli buffer and separated on SDSPAGE and transferred to polyvinylidene difluoride (PVDF) membranes (Immoblion-P, Millipore, Schaffhausen, Switzerland). After blocking nonspecific binding with $5 \%$ milk powder in Tris-buffered saline (TBS) containing $0.1 \%$ Tween-20 for 1 hour at room temperature, the blots were incubated overnight at $4^{\circ} \mathrm{C}$ with primary antibodies against NaPi-Ila $(1: 2,000)$ [8], aklotho $(1: 1,000 ; \mathrm{KO} 603 ;$ TransGenic Inc.) and $\beta$-actin 
(1:5,000; A5316; Sigma-Aldrich). After washing, blots were incubated with the appropriate secondary antibodies coupled to alkaline phosphatase (Promega AG, Dübendorf, Switzerland) for 1 hour at room temperature. Finally, after three washes with TBS-Tween $0.1 \%$, membranes were exposed to alkaline phosphatase CDP-Star substrate (Roche) for 5 minutes, and protein signals were detected on an LAS-4000 Luminescent Image Analyzer. Images were quantified with the Advanced Image Data Analyzer (AIDA; Raytest). The expression levels of $\mathrm{NaPi}$-lla and aklotho were normalized to the intensity of $\beta$-actin.

\section{Statistics}

Statistical significances were calculated using the Student's t-test or one-way ANOVA (Bonferroni) as indicated. $P<0.05$ was considered significant. Results are presented as means \pm SEM. 


\section{RESULTS}

\section{Erythropoietin stimulates FGF23 in humans}

We measured intact FGF23 (iFGF23) and the C-terminal fragment of FGF23 (C-term. FGF23) in healthy young volunteers injected either with placebo or a single high dose of rhEPO. Subjects were treated in a cross-over design serving as their own controls. Twenty-four hours after rhEPO injection, iFGF23 was unchanged but C-term. FGF23 was significantly elevated (Figure 1a, b).

\section{In mice, rhEPO stimulates both the C-terminal fragment of FGF23 and intact} FGF23

To examine the mechanisms underlying the association of EPO and FGF23 in humans, we examined the effects of rhEPO administration to mice. Male C57BL/6 mice were injected once per day intraperitoneally with rhEPO or its vehicle saline and mice examined 24 hours and 4 days later. Compared to controls, 4 days of rhEPO significantly increased both iFGF23 and C-term. FGF23, whereas a single injection of rhEPO increased only C-term. FGF23 (Figure 2a). To verify the biological activity of rhEPO, hematocrit, total plasma iron and liver hepcidin mRNA levels were assessed. rhEPO suppressed 24 hours after the first rhEPO injection hepcidin without detectable changes in hematocrit and iron whereas 4 days of rhEPO significantly increased hematocrit and lowered iron and hepcidin as expected (Figure 2b, c).

\section{rhEPO induced FGF23 is biologically active}

To investigate whether the rhEPO stimulated iFGF23 is biologically active, we examined the effects of FGF23 on its downstream targets, namely inorganic phosphate $(\mathrm{Pi})$, parathyroid hormone $(\mathrm{PTH})$, aklotho and 1,25 $(\mathrm{OH})_{2}$ vitamin $\mathrm{D}_{3}$ metabolism. Neither plasma Pi (Figure 3a) nor PTH levels (Figure 3b) changed at 
any time point after rhEPO delivery. However, the renal protein abundance of the FGF23 co-receptor aklotho was diminished after 4 days (Figure 3c). The protein abundance of the major renal phosphate cotransporter NaPilla was reduced after 4 days of EPO injections (Figure $3 \mathbf{d}$ ). The rhEPO induced increase in iFGF23 suppressed 1,25 $(\mathrm{OH})_{2}$ vitamin $\mathrm{D}_{3}$ as evident after 4 days (Figure 4a). In agreement with decreased systemic 1,25 $(\mathrm{OH})_{2}$ vitamin $\mathrm{D}_{3}$ levels, the renal mRNA levels of $1 \alpha-$ hydroxylase, Cyp27b1, and the vitamin D receptor, VDR were decreased upon 4 days of rhEPO delivery, whereas expression of the 24-hydroxylase, Cyp24a1, which inactivates 1,25 $(\mathrm{OH})_{2} \mathrm{D}_{3}$ did not show any significant changes at mRNA level (Figure 4b).

\section{rhEPO affects bone and bone marrow cell FGF23 expression}

To further characterize sources of elevated FGF23, we examined the mRNA abundance of FGF23 in bone (tibia) and isolated bone marrow. rhEPO induced FGF23 mRNA in bone marrow cells 24 hours and 4 days after injection whereas in bone no effect was detectable after 24 hours and a suppression of FGF23 mRNA was detected after 4 days (Figure 5a).

To specify which bone marrow cell population expresses FGF23, we performed immunostaining against FGF23 using specific cell markers. Erythroid progenitors and mature erythroblasts were identified by staining for CD71 (transferrin receptor). As shown in (Figure 5b) CD71 positive cells showed intense FGF23 staining in rhEPO treated mice but only faint staining was detected in saline treated mice. Cells positive for CD11c, a marker for dendritic cells, showed also some FGF23 staining in both saline and EPO injected animals (Figure 5d). Using a macrophage lineage marker, 
CD68, we did not detect any cells staining for CD68 and FGF23 (Figure 5c). In contrast, the myeloid lineage marker CD115 co-localized with FGF23 in saline and rhEPO treated mice (Figure 5e). Thus, immunostaining suggests that myeloid, dendritic and erythroid cells may be sources of FGF23.

We also assessed the bone and bone marrow mRNA expression of two known cellular modulators of FGF23 production, the $\mathrm{N}$-acetylgalactosaminyltransferase 3 (Galnt3) involved in stabilizing FGF23 and Phex, a modulator of FGF23 degradation [22,2] at 24 hours and 4 days after rhEPO administration. In bone, Galnt3 and Phex mRNA expression levels were unaltered after 24 hours and showed a non-significant trend to decrease after 4 days (Figure 6a). In bone marrow, Phex mRNA was not detectable and Galnt3 mRNA abundance did not change. The bone cell marker Runx2 decreased in bone marrow cells upon rhEPO injection (Figure 6b).

\section{The PHD inhibitor, roxadustat mimics the effect of rhEPO on FGF23 in mice}

To determine if stimulation of endogenous EPO production could also increase FGF23 levels, mice were treated for 4 days with the prolyl-4-hydroxylase domain (PHD) inhibitor, roxadustat with a dose and for a duration shown previously to stimulate EPO levels [34]. Roxadustat significantly increased the hematocrit and decreased mildly iron suggesting that it had been biologically active (Figure 7a). Furthermore, we showed that similar to exogenous rhEPO delivery, roxadustat elevated systemic intact FGF23 (Figure 7b).

To test whether chronically elevated levels of rhEPO impact on FGF23 levels, we used the well-characterized mouse EPO-Tg6 model overexpressing hEPO [32] and found elevated intact FGF23 levels (Figure 8). 


\section{FGF23 suppresses renal EPO expression}

EPO and FG23 may form a feedback loop with FGF23 reducing circulating EPO levels and inhibiting erythropoiesis [7]. In order to test whether an acute elevation of FGF23 would suppress renal EPO production, we injected mice with recombinant human intact FGF23 and assessed renal EPO mRNA abundance 30 min and 24 hours after injection. Indeed, FGF23 application reduced renal EPO mRNA levels by about 50\% within 30 min and this effect persisted for about 24 hours (Figure 9A). Injection of rhFGF23 resulted in very high rhFGF23 levels 30 min after injection and even $24 \mathrm{~h}$ after injection a significant amount of rhFGF23 was still detectable in blood of injected animals (Figure 9B). To test whether also elevations of endogenous FGF23 within the physiological range could affect renal EPO mRNA, mice were placed for 3 or 5 days on diets with low and high phosphate content. As expected, under these conditions, endogenous FGF23 levels were higher in the mice receiving the high phosphate diet and reached values comparable to those measured after 24 $\mathrm{h}$ in the rhFGF23 injected mice (Figure 9D). Importantly, renal EPO mRNA was significantly lower in the high phopshate group after 3 days but not after 5 days (Figure 9C). 


\section{DISCUSSION}

In the present study we examined the stimulatory effect of EPO on FGF23, a major endocrine regulator of phosphate and 1,25 $(\mathrm{OH})_{2}$ vitamin D3 metabolism. Our results demonstrate that 1) injection of a single high dose rhEPO in healthy human subjects increased the C-term. FGF23 fragment but not iFGF23, 2) injection of rhEPO in mice stimulated C-term. and iFGF23 but with different time-dependency 3) rhEPO induced iFGF23 is biologically active, 4) rhEPO induced FGF23 mRNA in bone marrow cells and FGF23 staining in CD71+ erythroid progenitor cells, 5) the effect of rhEPO was mimicked by a PHD inhibitor, 6) chronically elevated EPO in EPO-Tg6 mice was associated with higher iFGF23 levels, and 7) acute application of recombinant human FGF23 as well as raising endogenous FGF23 levels with a high phosphate diet reduces renal EPO expression in mice.

In human patients with chronic kidney disease (CKD) positive associations have been shown between low iron status and high C-term. FGF23 as well as between high C-term. FGF23 and anemia [25]. In mice with FGF23 mutations, iron modulates FGF23 levels [4] and acute blood loss in normal mice increases C-term. FGF23 [26]. Whether the effect of iron on FGF23 is mediated by or dependent on EPO and whether FGF23 causes anemia (and vice versa) has not been tested in humans. However, a recent study in 4 patients with anemia of non-CKD origin showed that a single dose of EPO increased both C-term. FGF23 and iFGF23 [5]. In critically ill patients the number of blood transfusions positively associated with C-term. FGF23 levels [26]. In patients with acute kidney injury (AKI), circulating levels of EPO increase and correlate with higher levels of C-term. and iFGF23 [31]. Additionally, another recent study demonstrated that blocking FGF23 signalling in a mouse CKD 
model could ameliorate renal anemia by releasing the blockade of renal EPO expression and by increasing iron availability through reduction of hepatic inflammation [1]. In our study, in 28 healthy volunteers injected with a single dose of rhEPO only C-term. FGF23 was elevated after 24 hours. However, it cannot be excluded that iFGF23 changed at an earlier or later point and that our measurements missed this time point.

We used animal experiments in C57BL/J mice to further examine the underlying mechanisms and to elucidate directly causative relationships between EPO and FGF23. Injection of rhEPO into mice at doses previously shown to induce hematopoiesis [13] stimulated C-term. FGF23 after 24 hours and both C-term. and iFGF23 after 4 days. This effect of rhEPO on iFGF23 was mimicked by the PHD inhibitor roxadustat. This was confirmed by a higher hematocrit in our mice treated with roxadustat. Our results are in partial agreement with other observations. Flamme et al. showed that acute application of rhEPO induces both C-term. and iFGF23 within 4-6 hours even though it appeared that iFGF23 was rising slower and experiments were carried out in rats and not in mice [12]. The same authors found also that another PHD inhibitor (molidustat) increased C-term. and iFGF23 but with higher sensitivity towards C-term. FGF23 [12]. Likely, the effect of PHD inhibitors on FGF23 is mediated by stimulating EPO production and release and does not involve direct effects of the drugs on FGF23 synthesis (or via elevated HIF on FGF23 transcription) as exposure of erythroid cells to a PHD inhibitor did not affect FGF23 mRNA levels and the stimulatory effect of a PHD inhibitor on FGF23 levels was abolished when mice were treated with EPO-neutralizing antibodies [12]. The effect of EPO on FGF23 is sustainable when EPO levels remain high, as evident from the elevated iFGF23 levels in the EPO-Tg6 mice that feature severalfold chronically 
elevated EPO levels [28]. Toro and colleagues showed that the effect of EPO on FGF23 is mediated by the homodimeric EPO-receptor in vitro and in vivo [31].

iFGF23 lowers plasma phosphate by downregulating renal sodium-phosphate cotransporters NaPilla and NaPillc to promote renal phosphate excretion [17]. Moreover, iFGF23 suppresses the levels of active $1,25(\mathrm{OH})_{2}$ vitamin $\mathrm{D}_{3}$ by reducing the expression of the activating enzyme Cpy27b1 and/or increasing the expression of the inactivating enzyme Cyp24a1 [17]. FGF23 modulates also the renal expression of its co-receptor aklotho and may acutely stimulate ( $3-24$ hours) its abundance [30] whereas the long-term effects are not well known. In order to analyze whether the increase in iFGF23 was biologically relevant we tested the modulation of these FGF23 targets and found that NaPilla, 1,25 (OH)2 vitamin $\mathrm{D}_{3}$, Cyp27b1, and aklotho were all lower in 4 days rhEPO treated mice, suggesting that the increased iFGF23 was sufficient to elicit a response on its downstream targets. The absence of lower plasma phosphate may be due to the short treatment duration and may require longer time to develop. Of note, rhEPO treatment had no effect on PTH levels, at least within the period of 4 days studied. However, the effects of chronically elevated EPO levels on FGF23 and mineral metabolism are currently unknown. Interestingly, EPO-Tg6 mice, as well as mice lacking the EPO regulator PHD, have been reported to suffer from a severe form of low bone mineralisation and osteopenia [16,27]. The defect may be in part due to direct stimulatory effects of EPO on osteoclast precursor cells [16] but it is tempting to speculate that a combination of higher FGF23 and lower $1,25(\mathrm{OH})_{2}$ vitamin $\mathrm{D}_{3}$ with subsequent low systemic phosphate availability may contribute to the bone phenotype. Whether EPO substitution in patients may cause similar symptoms is unknown. 
Bone cells, mostly osteocytes, are the major source of circulating FGF23 and are the targets of factors regulating FGF23 levels [17]. EPO receptors have been described in bone cells but the major target of EPO are cells of the erythroid lineage present in bone marrow [29]. Thus, we examined mRNA expression of FGF23 separately in bone and bone marrow. Acute rhEPO (24 hours) had no effect on bone FGF23 mRNA but induced it in bone marrow as described before [26]. After 4 days the induction of FGF23 mRNA in bone marrow persisted whereas FGF23 mRNA in bone was reduced. The downregulation of FGF23 mRNA in bone may be reactive to elevated systemic FGF23 levels. We used immunohistochemistry on bone marrow cells isolated from mice treated for 4 days with saline or rhEPO. Our results suggest that at baseline FGF23 is expressed in few cells positive for the myeloid lineage marker CD115 and the dendritic cell marker CD11c, consistent with other reports that these cells can express FGF23 [23]. Importantly, CD71 positive cells from the erythroid lineage had no or only faint FGF23 staining in unstimulated animals but showed much stronger staining in rhEPO treated mice. This finding is in agreement with other reports describing the presence of FGF23 mRNA in Ter119+ erythroid cells $[7,21,31]$ and FGF23 mRNA stimulation by EPO in the murine BAF3 erythroid cell line [12]. However, Clinkenbeard et al. reported that rhEPO induced FGF23 mRNA in both bone and bone marrow and pharmacological ablation of bone marrow reduced C-term. FGF23 induction but only by about 40\% [5]. Thus, EPO stimulates FGF23 production by bone marrow cells, most likely erythroid precursors. Whether bone derived FGF23 contributes to the elevation of FGF23 levels remains to be clarified. We had tried to further test whether changes in expression of FGF23 modulating factors in bone or bone marrow contributes to changes in circulating iFGF23 and Cterm. FGF23, but results on the expression of Galnt3 and Phex remained inconclusive and the role of FGF23 modifying factors has to be further addressed. 
Increased EPO levels and stimulated erythropoiesis in mice lacking FGF23 have been reported [7]. Conversely, application of FGF23 to normal mice reduced circulating EPO levels and decreased erythropoiesis. We demonstrated here that FGF23 also reduced renal EPO mRNA expression within minutes after application. Likewise, raising endogenous FGF23 levels with a diet containing high phosphate, was also associated with lower renal EPO mRNA levels. However, this effect seemed to disappear after 5 days of high phosphate diet. The effect of FGF23 on EPO and erythropoiesis was mostly independent from the effects of FGF23 on 1,25- $(\mathrm{OH})_{2}$ vitamin $D_{3}$ and the ability of $1,25-(O H)_{2}$ vitamin $D_{3}$ to stimulate erythropoiesis and suppress hepcidin, a major regulator of iron availability [7]. FGF23 may (directly or indirectly) affect EPO mRNA stability or transcription [15,24]. Further studies on renal cells expressing EPO may provide insights into the exact mechanism how FGF23 regulates EPO mRNA abundance. Thus, EPO and FGF23 may be linked in a feedback loop where EPO stimulates FGF23 which in turn suppresses EPO. In addition, FGF23 appears to have direct and indirect effects on erythropoiesis. A model illustrated in figure 10 may summarize some of the regulatory loops involved in the regulation of erythropoiesis by EPO, FGF23 and 1,25- $(\mathrm{OH})_{2}$ vitamin $\mathrm{D}_{3}$. EPO stimulates erythropoiesis and FGF23 reduces erythropoiesis in at least three ways, by blocking EPO, by reducing 1,25- $(\mathrm{OH})_{2}$ vitamin $\mathrm{D}_{3}$ stimulating erythropoiesis and by direct negative effects on erythropoiesis. In CKD, FGF23 may also be involved in increasing proinflammatory cytokines which in turn reduce iron availability [1]. The model may also further shed light on mechanism by which inflammation can reduce erythropoiesis: inflammation reduces iron availability and stimulates FGF23 both reducing erythropoiesis. Consistently, EPO increases levels of C-term. FGF23 and iFGF23 and the rise in C-term. FGF23 may precede iFGF23 and may have a higher 
sensitivity. At least one report suggested that C-term. FGF23 could occupy FGF receptors and render them less responsive to iFGF23 [14]. It could be speculated that the earlier EPO-induced increase in C-term. FGF23 might allow for a transient stronger stimulation of erythropoiesis before iFGF23 rises. Clearly, the biology underlying the link of mineral metabolism and erythropoiesis requires further clarification.

\section{Acknowledgements}

This study has been supported by the Swiss National Science Foundation (SNSF) through the National Center for Competence in Research NCCR Kidney.CH and the SNSF funded projects 31003A_176125 to C.A.W., 31003A_165679 to R.H.W., and 31003A_156481 to M.G. 


\section{FIGURE LEGENDS}

\section{Figure 1}

Acute treatment of healthy human subjects with high dose rhEPO increased Cterm. FGF23 but not iFGF23.

Healthy human subjects were injected with placebo or high dose rhEPO in a crossover experiment and intact FGF23 (iFGF23) and C-terminal FGF23 (C-term. FGF23) measured. $n=28$, significance was determined using the paired Student's $t$-test with ${ }^{*} p<0.05$.

\section{Figure 2}

rhEPO injection increased circulating levels of intact FGF23 and C-term. fragment of FGF23 in mice

Mice were injected for 24 hours or 4 days either with saline or rhEPO. (a) C-terminal (C-term.) and intact FGF23 levels in plasma, (b) markers of EPO activity, plasma hematocrit and total iron levels, (c) Liver hepcidin mRNA expression. $n=5$ for each group of mice. Significance was determined with the unpaired Student's $t$-test with ${ }^{*} p$ $<0.05,{ }^{* *} p<0.01$.

\section{Figure 3}

rhEPO injection did not change plasma levels of $\mathrm{Pi}$ and $\mathrm{PTH}$, but rather decreased the expression of renal sodium-phosphate co-transporter NaPi-lla and $\alpha$ klotho

Mice were injected for 24 hours or 4 days either with saline or rhEPO. (a) Plasma concentrations of $\mathrm{Pi}$, (b) plasma parathyroid hormone (PTH). Immunblotting for (c) aklotho and (d) the renal sodium-phosphate co-transporter NaPi-lla in kidney. 
Immunoblot membranes were stripped and re-probed for $\beta$-actin. Scatter blots show ratios of aklotho or NaPill-a over $\beta$-actin. $n=5$ for each group of mice, significance was determined by unpaired Student's $t$-test with ${ }^{* *} p<0.01$.

\section{Figure 4}

rhEPO injection decreased plasma levels of $1,25(\mathrm{OH})_{2}$ vitamin $D_{3}$ and expression of renal vitamin D regulating transcripts.

Mice were injected for 24 hours or 4 days either with saline or rhEPO. (a) Plasma levels of $1,25(\mathrm{OH})_{2}$ D3, (b) Renal mRNA expression of the vitamin $\mathrm{D}_{3}$-metabolizing enzymes Cyp27b1 and Cyp24a1 and the vitamin D receptor VDR. $n=5$ for each group of mice, significance was determined by unpaired Student's $t$-test with ${ }^{*} p<$ 0.05 .

\section{Figure 5}

rhEPO induced FGF23 expression in bone marrow myeloid and erythroid cells. Mice were injected for 24 hours or 4 days either with saline or rhEPO and bone and bone marrow isolated. (a) FGF23 mRNA levels in bone and bone marrow cells normalized to HPRT. Data are means \pm SEM; $n=5$, significance determined by unpaired Student's $t$-test with ${ }^{*} p<0.05$ and ${ }^{* *} p<0.001$. (b-e) Representative immunofluorescence images of fixed bone marrow cells populations from mice treated for 4 days either with saline or rhEPO: (b) erythroid lineage marker CD71 (red), FGF23 (green) and DNA dye DAPI (blue), (c) Macrophage marker CD68 (red) and FGF23 (green) and DNA dye DAPI (blue), (d) dendritic cell marker CD11c (red), FGF23 (green) and DNA dye DAPI (blue), (e) monocyte marker CD115 (red), FGF23 (green) and DNA dye DAPI (blue). Original magnification 400-630x. 


\section{Figure 6}

rhEPO altered expression of factors involved in FGF23 metabolism in bone and bone marrow cells.

Mice were injected for 24 hours or 4 days either with saline or rhEPO, and bone and bone marrow isolated. (a) mRNA expression of Phex and Galnt3 in bone, (b) mRNA abundance of Galnt3 and Runx2 in bone marrow cells. $n=5$ for each group, significance determined by unpaired Student's $t$-test with ${ }^{* *} p<0.01$.

\section{Figure 7}

The PHD inhibitor roxadustat (FG-4592) mimicked the effect of rhEPO on FGF23.

Mice were treated for 4 days with roxadustat (50 mg/kg/daily) or vehicle. (a) Plasma hematocrit and total iron levels, (b) plasma intact FGF23. $n=5$ for each group, significance was determined by unpaired Students t-test with ${ }^{*} p<0.05$.

\section{Figure 8}

Transgenic mice over-expressing human EPO (EPO-Tg-6) had elevated iFGF23. iFGF23 was measured in mice overexpressing human EPO, $n=9$ WT/ 6 EPO-Tg6 mice. Significance was determined by the unpaired Student's $t$-test with ${ }^{*} p<0.05$.

\section{Figure 9}

rhFGF23 suppressed renal EPO mRNA expression in mouse kidney.

(A, B) Mice were injected with rhFGF23 or vehicle (saline) and EPO mRNA abundance assessed in kidneys 30 min or 24 hours after injection. Data were normalized to vehicle treated animals. rhFGF23 was measured using an ELISA only 
recognizing human but not mouse FGF23. (C, D) Mice were fed with low and high phosphate diets for 3 or 5 days and EPO mRNA and endogenous FGF23 levels determined. EPO mRNA data were normalized to animals for 3 days on low phosphate diet. $n=4-5 /$ group, significance determined by ANOVA test followed by Tukey post-test with ${ }^{*} p<0.05,{ }^{* *} p<0.01$ and ${ }^{* *} p<0.001$.

\section{Figure 10}

\section{Model linking EPO and FGF23}

Our data demonstrate a stimulatory effect of EPO on FGF23 production, as a feedback loop in mice which impacts mostly on 1,25 $(\mathrm{OH})_{2} \mathrm{D}_{3}$ levels and metabolism. In humans, the effect of EPO is mostly associated with the C-terminal fragment of FGF23 (C-term. FGF23). Elevated C-term. FGF23 may enhance the effects of EPO on erythropoiesis (by reducing the inhibitory effect of intact FGF23 (iFGF23)) whereas the later increase in iFGF23 would directly and indirectly reduce erythropoiesis. For more details see discussion. 


\section{References}

1. Agoro R, Montagna A, Goetz R, Aligbe O, Singh G, Coe LM, Mohammadi M, Rivella S, Sitara D (2018) Inhibition of fibroblast growth factor 23 (FGF23) signaling rescues renal anemia. FASEB J:fj201700667R. doi:10.1096/fj.201700667R

2. Bhattacharyya N, Chong WH, Gafni RI, Collins MT (2012) Fibroblast growth factor 23: state of the field and future directions. Trends Endocrinol Metab 23:610618. doi:10.1016/j.tem.2012.07.002

3. Chen G, Liu Y, Goetz R, Fu L, Jayaraman S, Hu MC, Moe OW, Liang G, Li X, Mohammadi M (2018) alpha-Klotho is a non-enzymatic molecular scaffold for FGF23 hormone signalling. Nature. doi:10.1038/nature25451

4. Clinkenbeard EL, Farrow EG, Summers LJ, Cass TA, Roberts JL, Bayt CA, Lahm T, Albrecht M, Allen MR, Peacock M, White KE (2014) Neonatal iron deficiency causes abnormal phosphate metabolism by elevating FGF23 in normal and ADHR mice. J Bone Miner Res 29:361-369. doi:10.1002/jbmr.2049

5. Clinkenbeard EL, Hanudel MR, Stayrook KR, Appaiah HN, Farrow EG, Cass TA, Summers LJ, Ip CS, Hum JM, Thomas JC, Ivan M, Richine BM, Chan RJ, Clemens TL, Schipani E, Sabbagh Y, Xu L, Srour EF, Alvarez MB, Kacena MA, Salusky IB, Ganz T, Nemeth E, White KE (2017) Erythropoietin stimulates murine and human fibroblast growth factor-23, revealing novel roles for bone and bone marrow. Haematologica 102:e427-e430. doi:10.3324/haematol.2017.167882

6. Clinkenbeard EL, White KE (2017) Heritable and acquired disorders of phosphate metabolism: Etiologies involving FGF23 and current therapeutics. Bone. doi:S8756-3282(17)30034-0 [pii]

10.1016/j.bone.2017.01.034

7. Coe LM, Madathil SV, Casu C, Lanske B, Rivella S, Sitara D (2014) FGF-23 is a negative regulator of prenatal and postnatal erythropoiesis. J Biol Chem 289:9795-9810. doi:10.1074/jbc.M113.527150

8. Custer M, Lötscher, M, Biber, J, Murer, H, Kaissling, B (1994) Expression of Na-Pi cotransport in rat kidney: localization by RT-PCR and immunohistochemistry. Am J Physiol 266:F767-774

9. Daryadel A, Bourgeois S, Figueiredo MF, Gomes Moreira A, Kampik NB, Oberli L, Mohebbi N, Lu X, Meima ME, Danser AH, Wagner CA (2016) Colocalization of the (Pro)renin Receptor/Atp6ap2 with H+-ATPases in Mouse Kidney but Prorenin Does Not Acutely Regulate Intercalated Cell H+-ATPase Activity. PLoS One 11:e0147831. doi:10.1371/journal.pone.0147831

PONE-D-15-01396 [pii]

10. Daryadel A, Grifone RF, Simon HU, Yousefi S (2006) Apoptotic neutrophils release macrophage migration inhibitory factor upon stimulation with tumor 
necrosis factor-alpha. J Biol Chem 281:27653-27661. doi:10.1074/jbc.M604051200

11. David V, Martin A, Isakova T, Spaulding C, Qi L, Ramirez V, ZumbrennenBullough KB, Sun CC, Lin HY, Babitt JL, Wolf M (2016) Inflammation and functional iron deficiency regulate fibroblast growth factor 23 production. Kidney Int 89:135-146. doi:S0085-2538(15)00028-9 [pii]

10.1038/ki.2015.290

12. Flamme I, Ellinghaus $P$, Urrego D, Kruger $T$ (2017) FGF23 expression in rodents is directly induced via erythropoietin after inhibition of hypoxia inducible factor proline hydroxylase. PLoS One 12:e0186979. doi:10.1371/journal.pone.0186979

13. Gammella E, Diaz V, Recalcati S, Buratti P, Samaja M, Dey S, Noguchi CT, Gassmann M, Cairo G (2015) Erythropoietin's inhibiting impact on hepcidin expression occurs indirectly. Am J Physiol Regul Integr Comp Physiol 308:R330-335. doi:10.1152/ajpregu.00410.2014

14. Goetz R, Nakada Y, Hu MC, Kurosu H, Wang L, Nakatani T, Shi M, Eliseenkova AV, Razzaque MS, Moe OW, Kuro-o M, Mohammadi M (2010) Isolated Cterminal tail of FGF23 alleviates hypophosphatemia by inhibiting FGF23FGFR-Klotho complex formation. Proc Natl Acad Sci U S A 107:407-412. doi:0902006107 [pii]

10.1073/pnas.0902006107

15. Goldberg MA, Gaut CC, Bunn HF (1991) Erythropoietin mRNA levels are governed by both the rate of gene transcription and posttranscriptional events. Blood 77:271-277

16. Hiram-Bab S, Liron T, Deshet-Unger N, Mittelman M, Gassmann M, Rauner M, Franke K, Wielockx B, Neumann D, Gabet Y (2015) Erythropoietin directly stimulates osteoclast precursors and induces bone loss. FASEB J 29:18901900. doi:10.1096/fj.14-259085

17. Hu MC, Shiizaki K, Kuro-o M, Moe OW (2013) Fibroblast growth factor 23 and Klotho: physiology and pathophysiology of an endocrine network of mineral metabolism. Annu Rev Physiol 75:503-533. doi:10.1146/annurev-physiol030212-183727

18. Ito $N$, Wijenayaka AR, Prideaux $M$, Kogawa $M$, Ormsby RT, Evdokiou $A$, Bonewald LF, Findlay DM, Atkins GJ (2015) Regulation of FGF23 expression in IDG-SW3 osteocytes and human bone by pro-inflammatory stimuli. Mol Cell Endocrinol 399:208-218. doi:S0303-7207(14)00318-9 [pii]

10.1016/j.mce.2014.10.007

19. Kurt B, Gerl K, Karger C, Schwarzensteiner I, Kurtz A (2015) Chronic hypoxiainducible transcription factor-2 activation stably transforms juxtaglomerular renin cells into fibroblast-like cells in vivo. J Am Soc Nephrol 26:587-596. doi:10.1681/ASN.2013111152 
20. Lindberg K, Amin R, Moe OW, Hu MC, Erben RG, Ostman Wernerson A, Lanske $\mathrm{B}$, Olauson $\mathrm{H}$, Larsson TE (2014) The kidney is the principal organ mediating klotho effects. J Am Soc Nephrol 25:2169-2175. doi:ASN.2013111209 [pii]

10.1681/ASN.2013111209

21. Liu S, Zhou J, Tang W, Jiang X, Rowe DW, Quarles LD (2006) Pathogenic role of Fgf23 in Hyp mice. Am J Physiol Endocrinol Metab 291:E38-49

22. Martin A, David V, Quarles LD (2012) Regulation and function of the FGF23/klotho endocrine pathways. Physiol Rev 92:131-155. doi:92/1/131 [pii] 10.1152/physrev.00002.2011

23. Masuda Y, Ohta H, Morita Y, Nakayama Y, Miyake A, Itoh N, Konishi M (2015) Expression of Fgf23 in activated dendritic cells and macrophages in response to immunological stimuli in mice. Biol Pharm Bull 38:687-693. doi:10.1248/bpb.b14-00276

24. McGary EC, Rondon IJ, Beckman BS (1997) Post-transcriptional regulation of erythropoietin mRNA stability by erythropoietin mRNA-binding protein. J Biol Chem 272:8628-8634

25. Mehta R, Cai X, Hodakowski A, Lee J, Leonard M, Ricardo A, Chen J, Hamm L, Sondheimer J, Dobre M, David V, Yang W, Go A, Kusek JW, Feldman H, Wolf M, Isakova T (2017) Fibroblast Growth Factor 23 and Anemia in the Chronic Renal Insufficiency Cohort Study. Clin J Am Soc Nephrol 12:1795-1803. doi:CJN.03950417 [pii]

10.2215/CJN.03950417

26. Rabadi S, Udo I, Leaf DE, Waikar SS, Christov M (2018) Acute blood loss stimulates fibroblast growth factor 23 production. Am J Physiol Renal Physiol 314:F132-F139. doi:ajprenal.00081.2017 [pii]

10.1152/ajprenal.00081.2017

27. Rauner M, Franke K, Murray M, Singh RP, Hiram-Bab S, Platzbecker U, Gassmann M, Socolovsky M, Neumann D, Gabet Y, Chavakis T, Hofbauer LC, Wielockx B (2016) Increased EPO Levels Are Associated With Bone Loss in Mice Lacking PHD2 in EPO-Producing Cells. J Bone Miner Res 31:18771887. doi:10.1002/jbmr.2857

28. Ruschitzka FT, Wenger RH, Stallmach T, Quaschning T, de Wit C, Wagner K, Labugger R, Kelm M, Noll G, Rulicke T, Shaw S, Lindberg RL, Rodenwaldt B, Lutz H, Bauer C, Luscher TF, Gassmann M (2000) Nitric oxide prevents cardiovascular disease and determines survival in polyglobulic mice overexpressing erythropoietin. Proc Natl Acad Sci U S A 97:11609-11613. doi:10.1073/pnas.97.21.11609

97/21/11609 [pii]

29. Shiozawa Y, Jung Y, Ziegler AM, Pedersen EA, Wang J, Wang Z, Song J, Lee $\mathrm{CH}$, Sud S, Pienta KJ, Krebsbach PH, Taichman RS (2010) Erythropoietin couples hematopoiesis with bone formation. PLoS One 5:e10853. doi:10.1371/journal.pone.0010853 
30. Takenaka T, Watanabe Y, Inoue T, Miyazaki T, Suzuki H (2013) Fibroblast growth factor 23 enhances renal klotho abundance. Pflugers Arch 465:935943. doi:10.1007/s00424-013-1226-z

31. Toro L, Barrientos V, Leon P, Rojas M, Gonzalez M, Gonzalez-lbanez A, Illanes S, Sugikawa K, Abarzua N, Bascunan C, Arcos K, Fuentealba C, Tong AM, Elorza AA, Pinto ME, Alzamora R, Romero C, Michea L (2018) Erythropoietin induces bone marrow and plasma fibroblast growth factor 23 during acute kidney injury. Kidney Int. doi:10.1016/j.kint.2017.11.018

32. Vogel J, Gassmann M (2011) Erythropoietic and non-erythropoietic functions of erythropoietin in mouse models. J Physiol 589:1259-1264. doi:10.1113/jphysiol.2010.196147

33. Wolf M, Koch TA, Bregman DB (2013) Effects of iron deficiency anemia and its treatment on fibroblast growth factor 23 and phosphate homeostasis in women. J Bone Miner Res 28:1793-1803. doi:10.1002/jbmr.1923

34. Wu K, Zhou K, Wang Y, Zhou Y, Tian N, Wu Y, Chen D, Zhang D, Wang X, Xu H, Zhang $X$ (2016) Stabilization of HIF-1alpha by FG-4592 promotes functional recovery and neural protection in experimental spinal cord injury. Brain Res 1632:19-26. doi:S0006-8993(15)00956-7 [pii]

10.1016/j.brainres.2015.12.017

35. Zhang B, Umbach AT, Chen H, Yan J, Fakhri H, Fajol A, Salker MS, Spichtig D, Daryadel A, Wagner CA, Foller M, Lang F (2016) Up-regulation of FGF23 release by aldosterone. Biochem Biophys Res Commun 470:384-390. doi:S0006-291X(16)30034-1 [pii]

10.1016/j.bbrc.2016.01.034

36. Zhang B, Yan J, Umbach AT, Fakhri H, Fajol A, Schmidt S, Salker MS, Chen H, Alexander D, Spichtig D, Daryadel A, Wagner CA, Foller M, Lang F (2016) NFkappaB-sensitive Orai1 expression in the regulation of FGF23 release. $J$ Mol Med (Berl) 94:557-566. doi:10.1007/s00109-015-1370-3

10.1007/s00109-015-1370-3 [pii] 
a

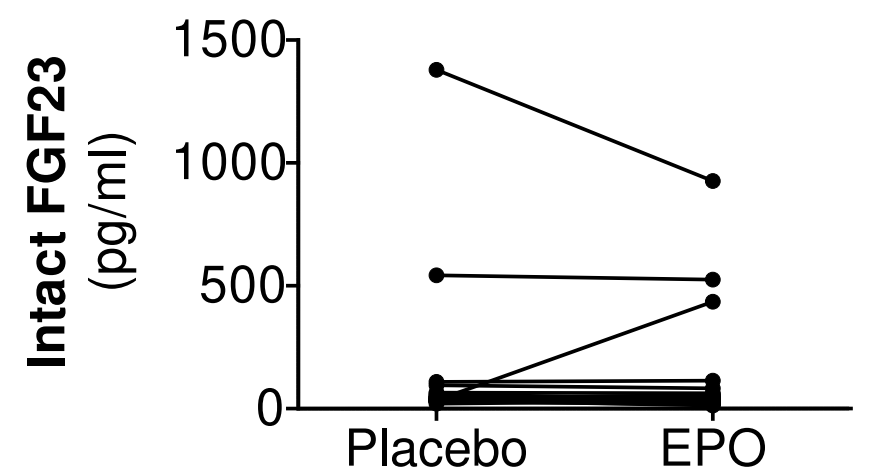

b

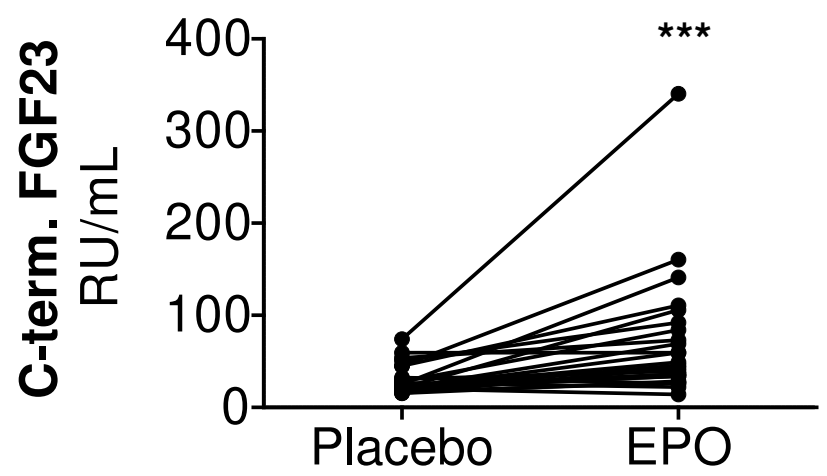


a
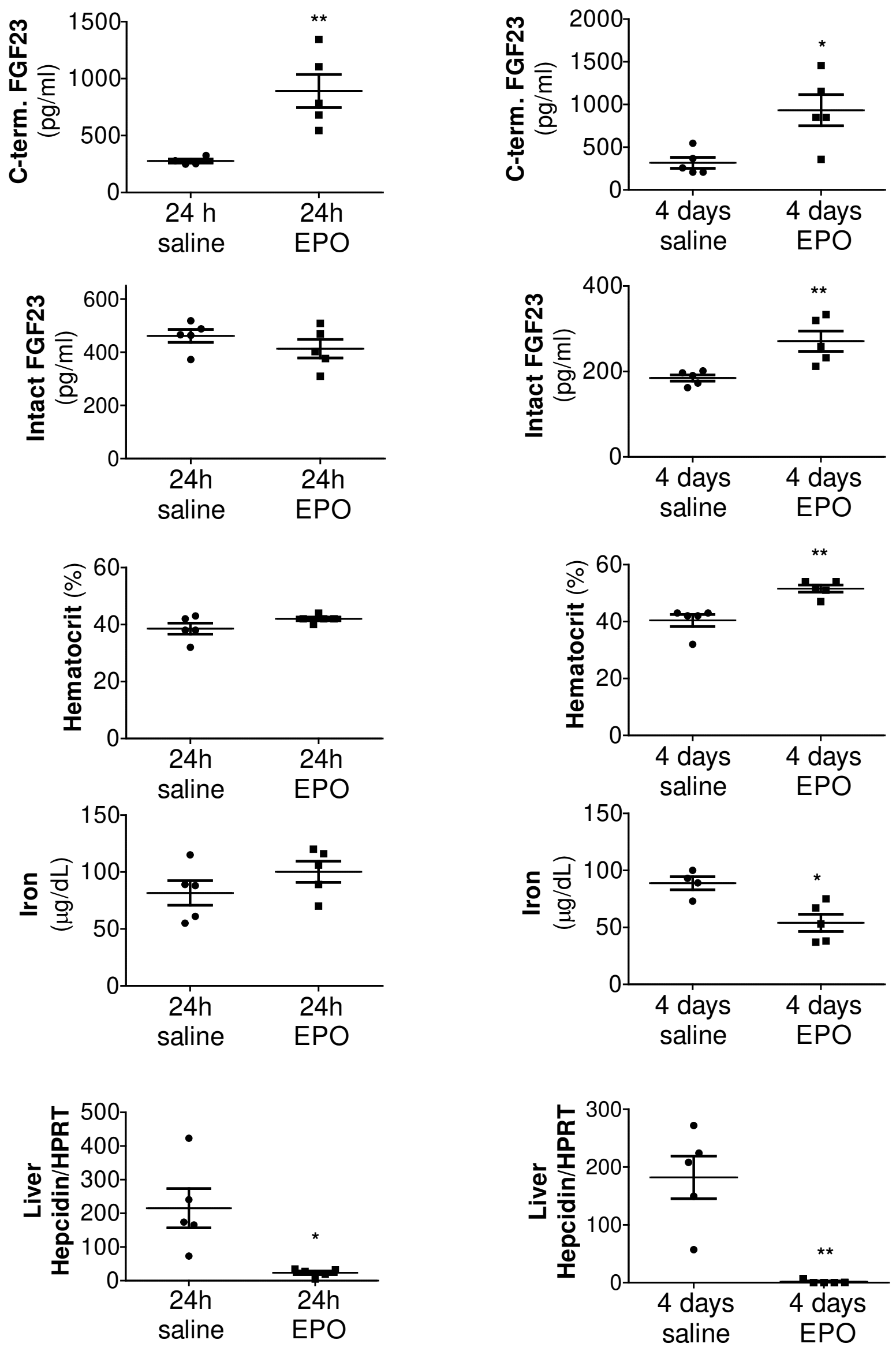
a

b
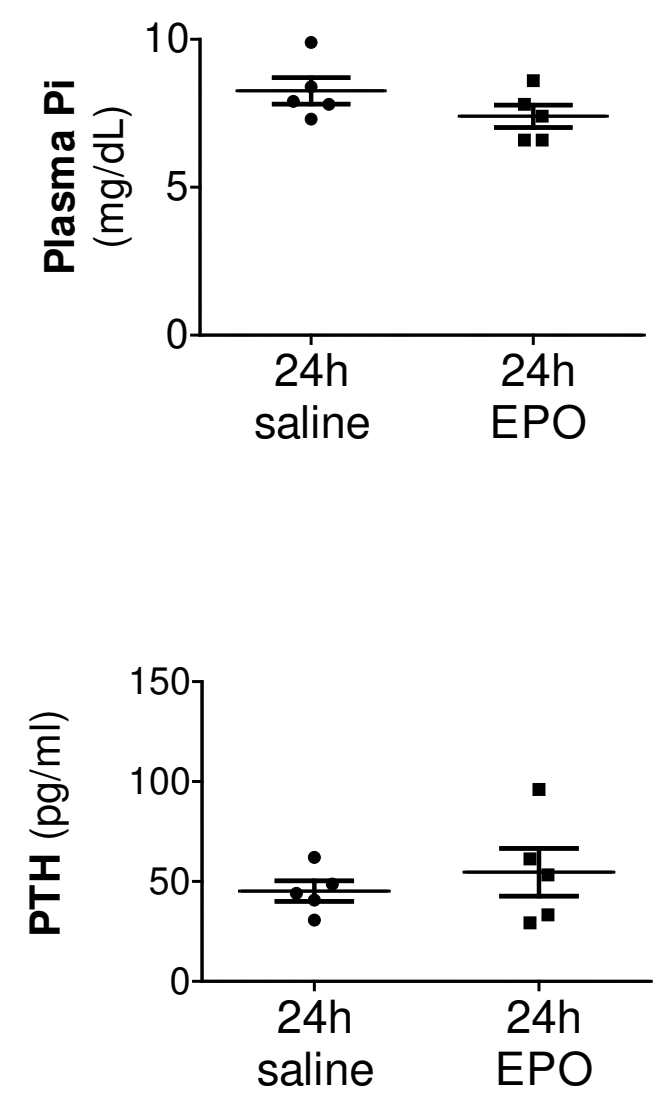

C

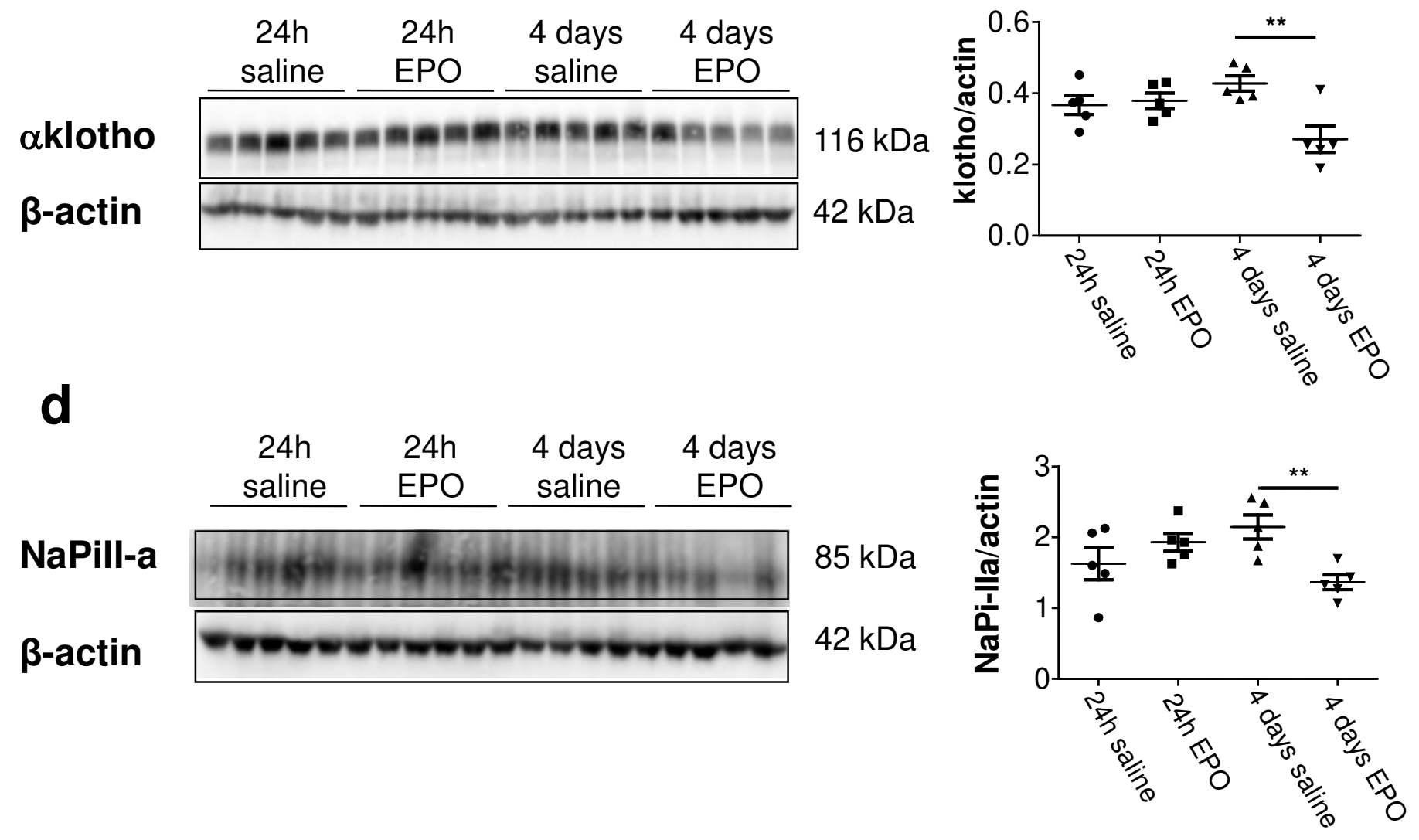

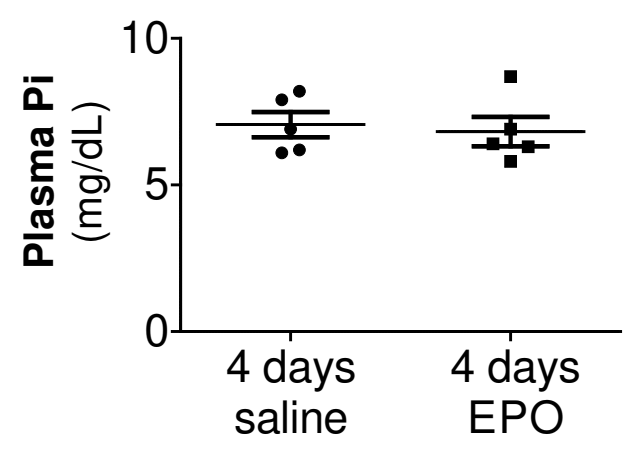

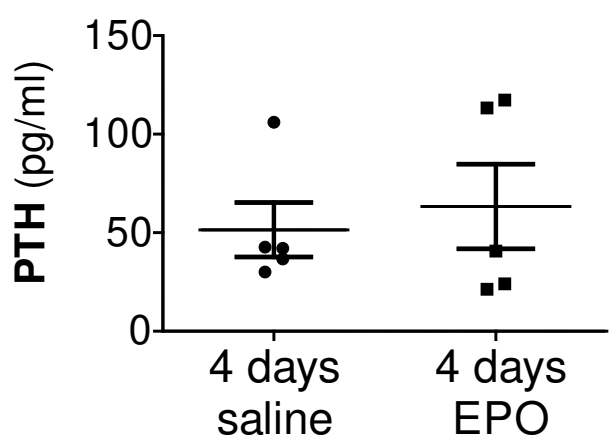


a

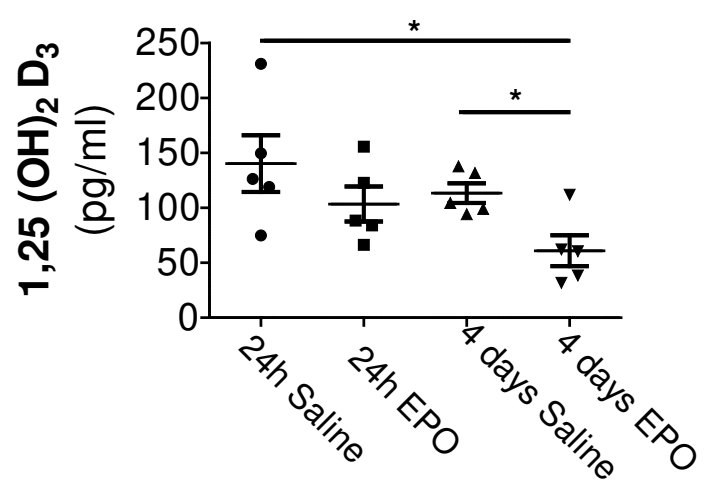

b
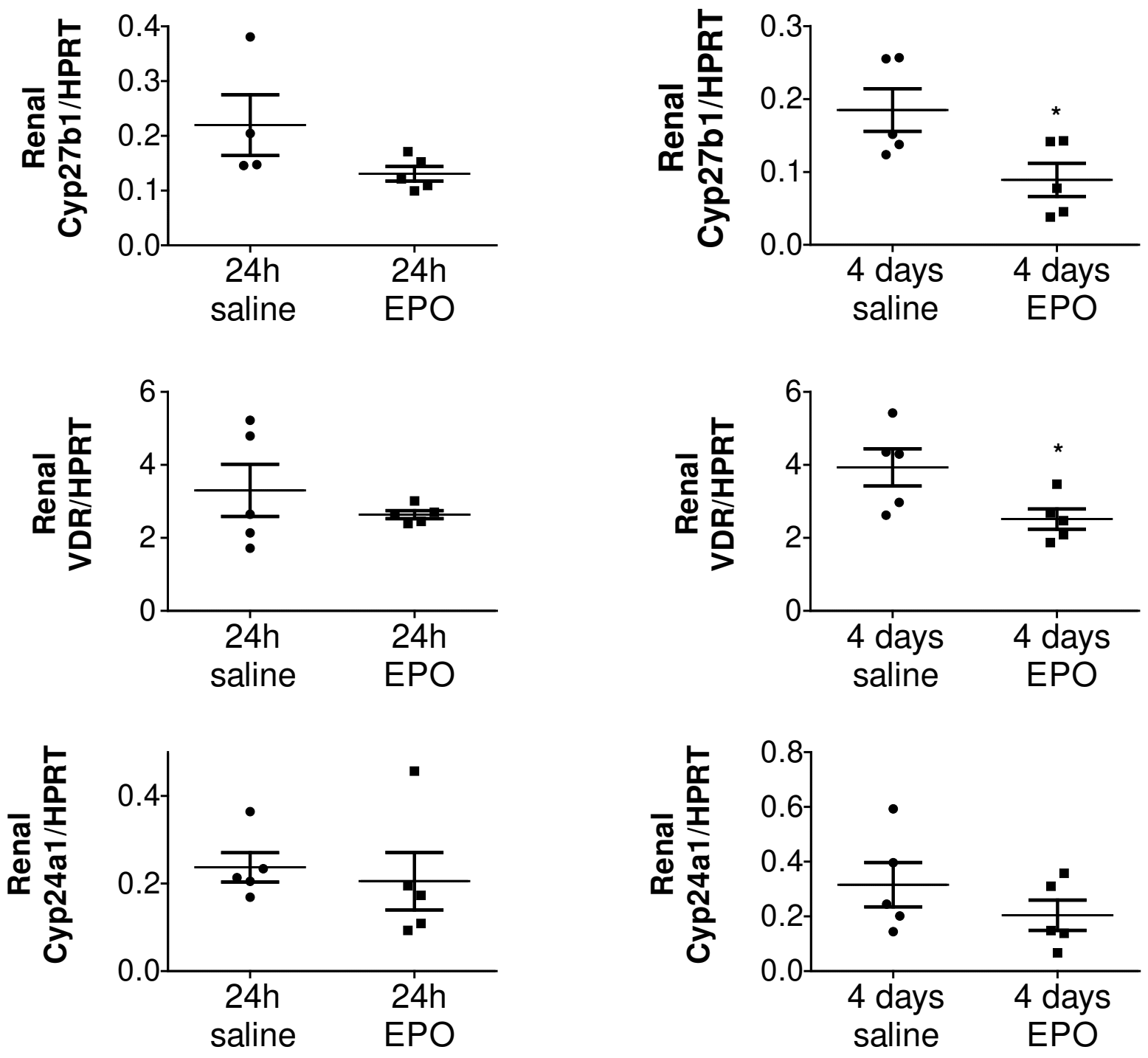
a

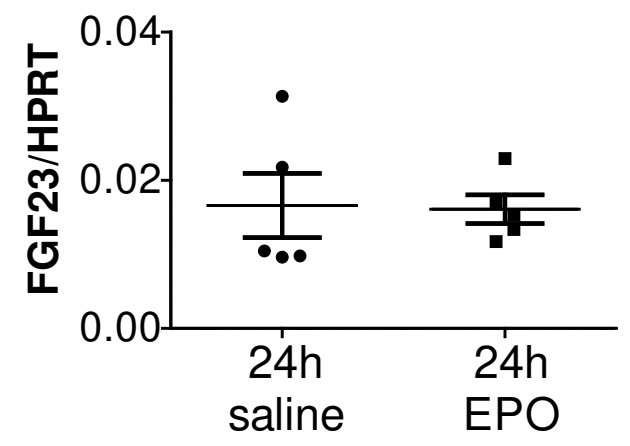

\section{Bone}

\section{Bone marrow}
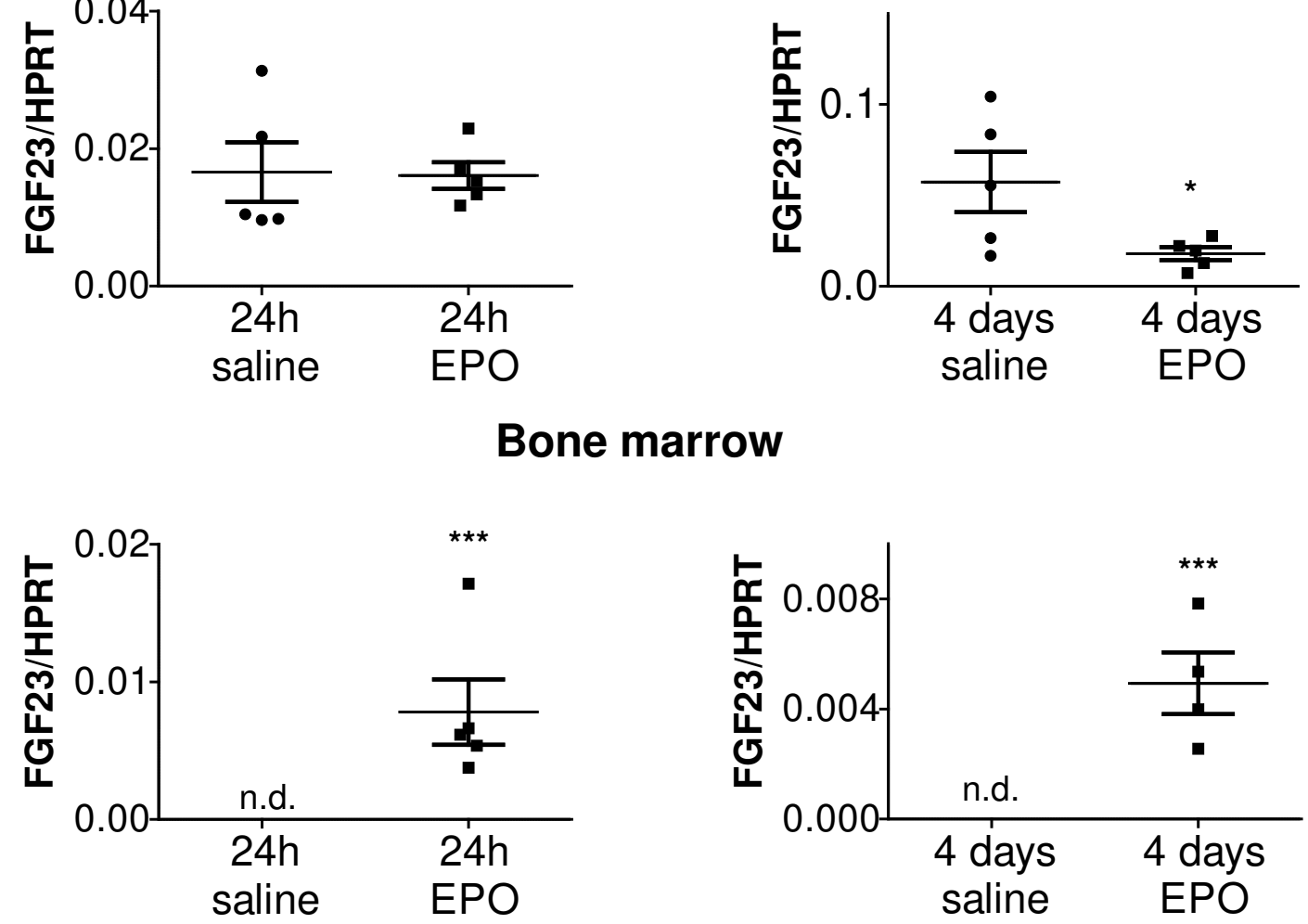
saline EPO 

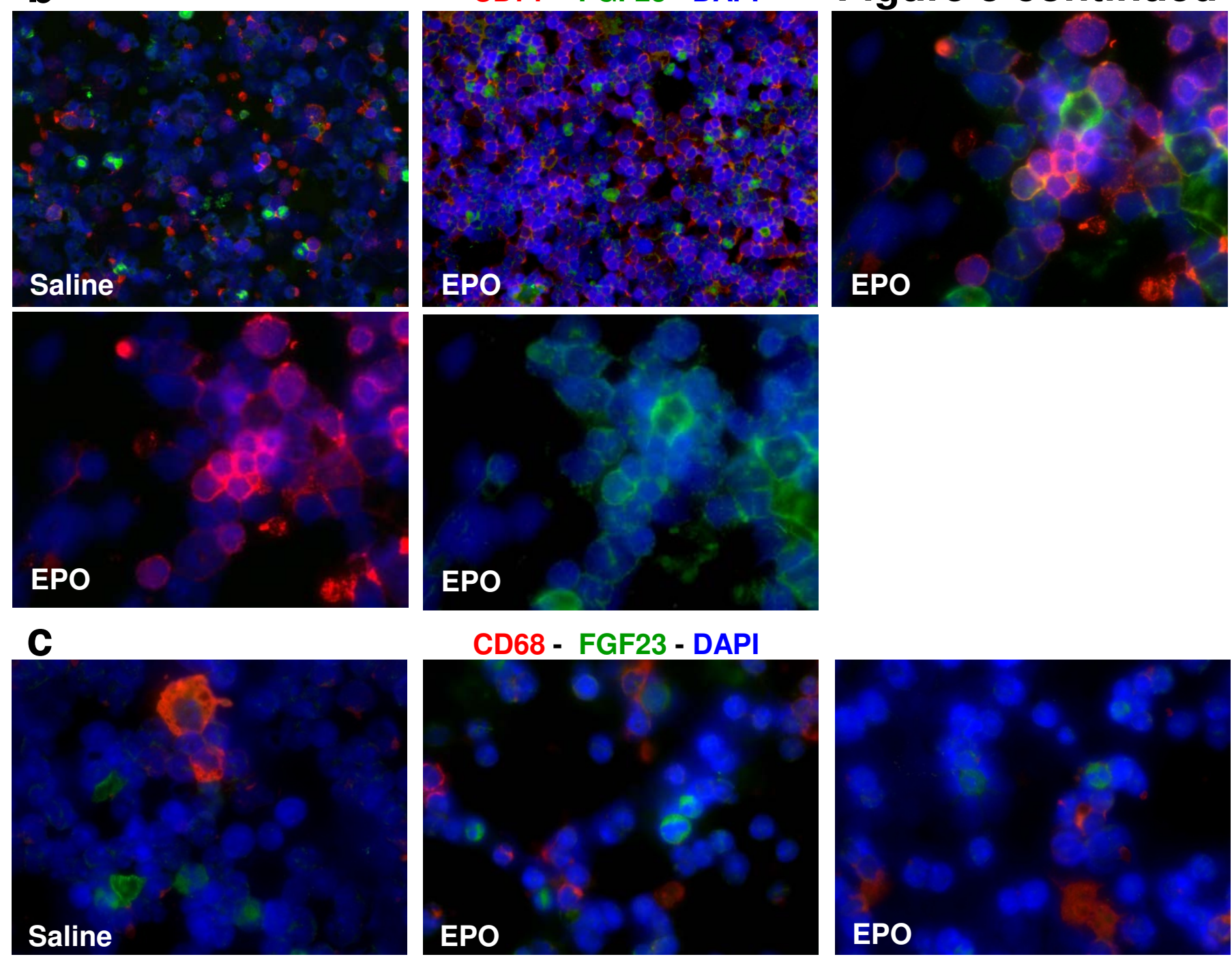

EPO

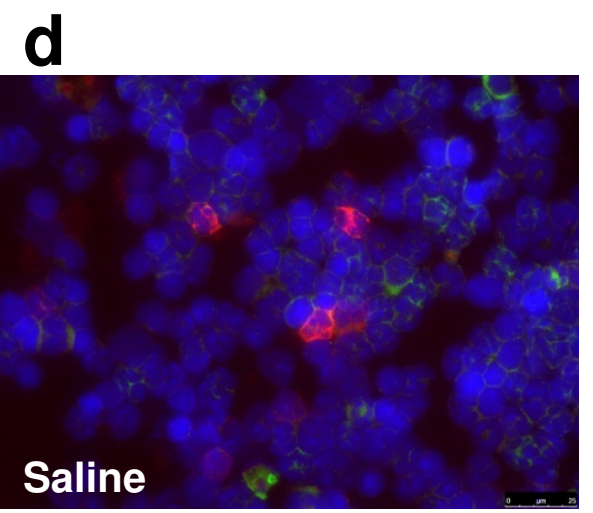

CD11c - FGF23 - DAPI
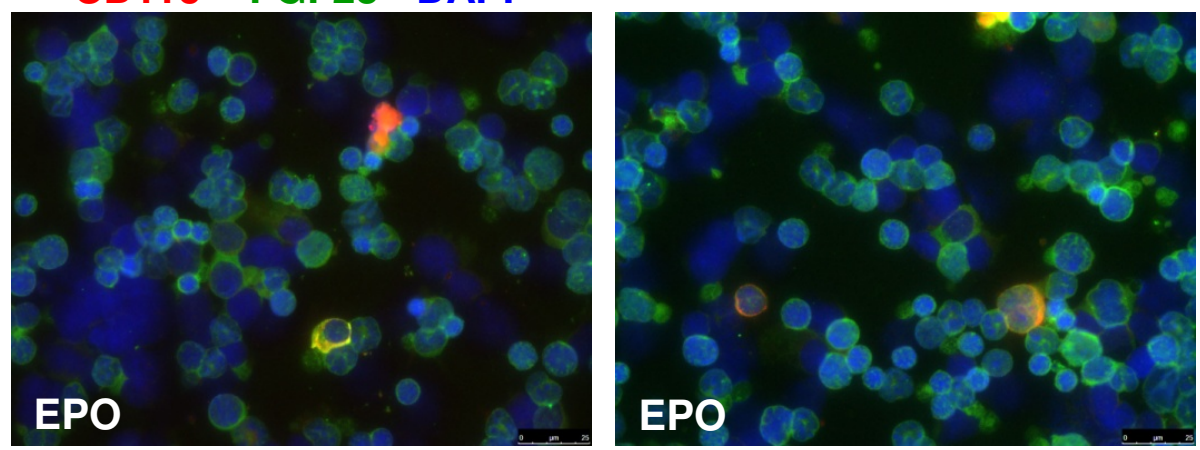

e

CD115 - FGF23 - DAPI 
a

\section{Bone}
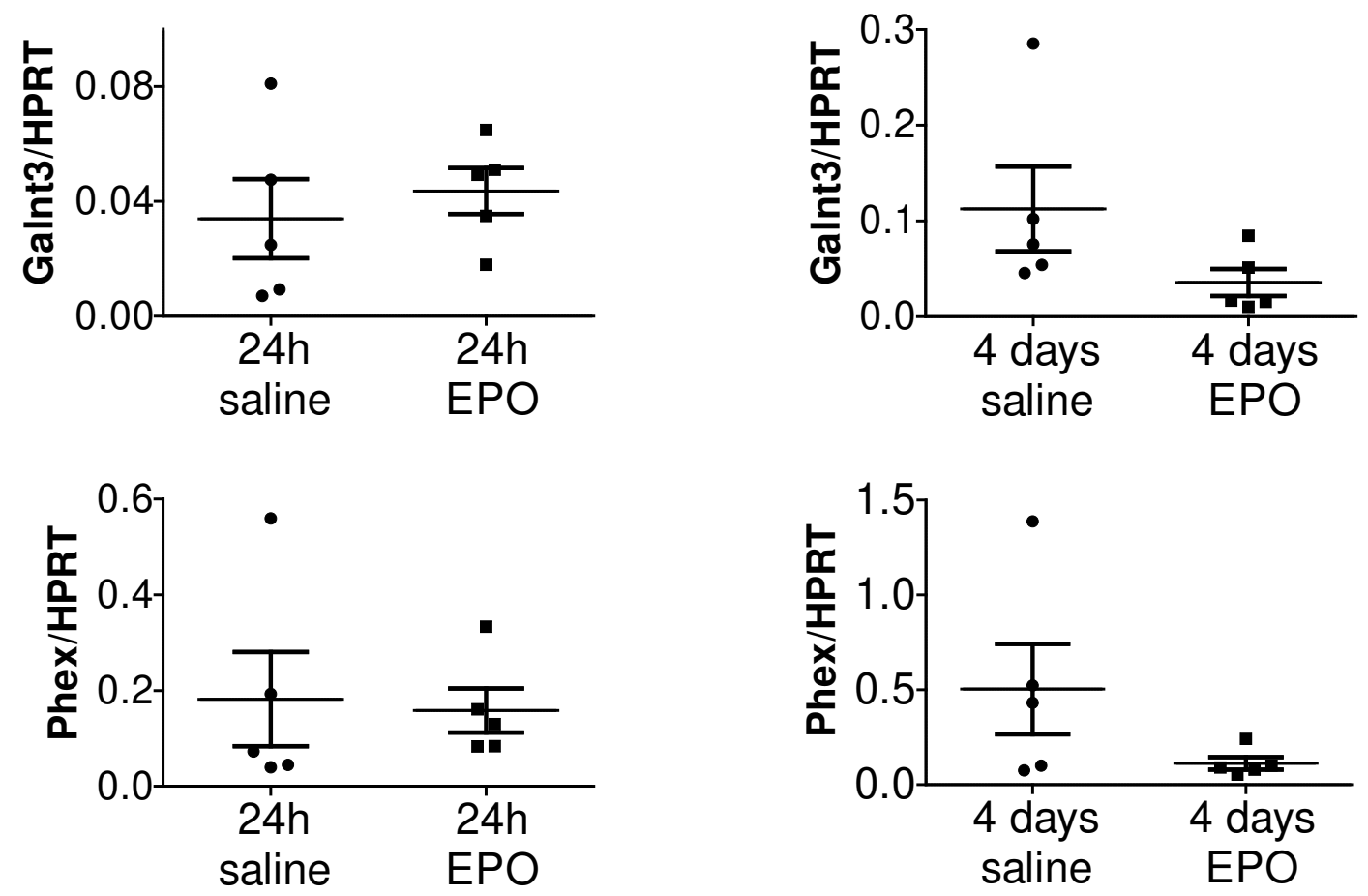

b

Bone marrow
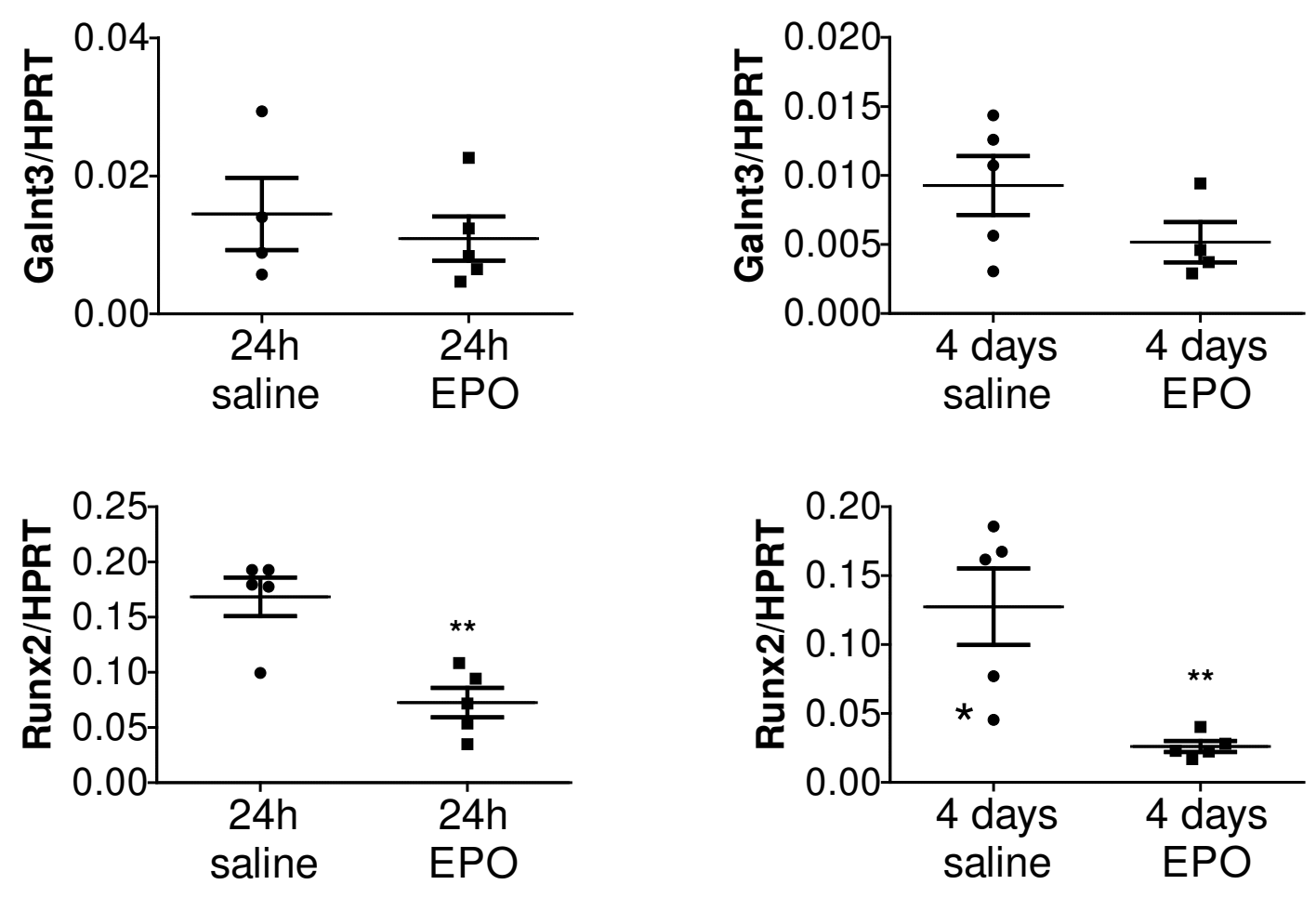
a
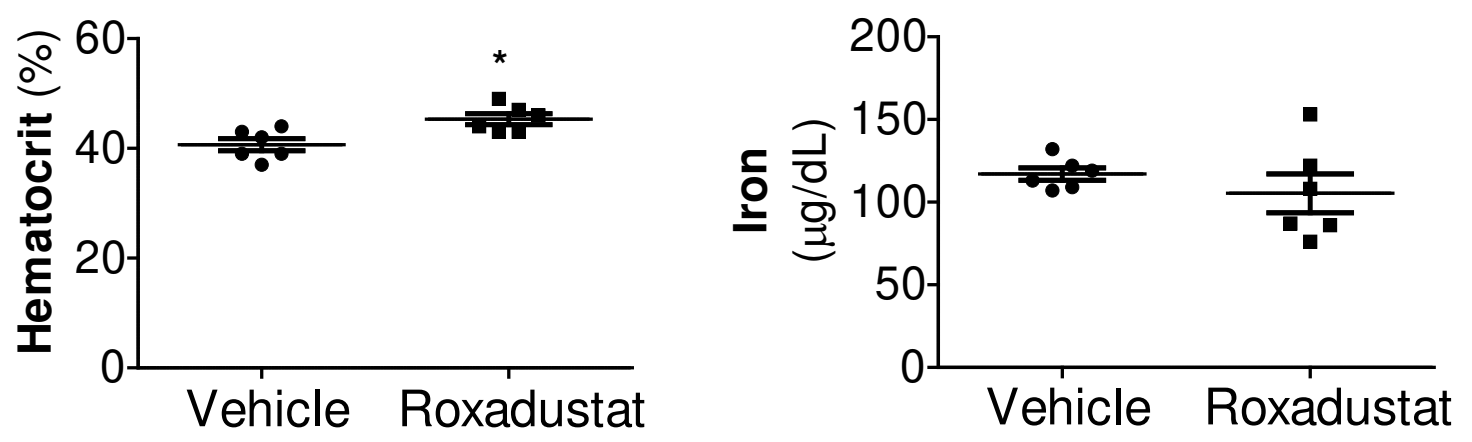

b

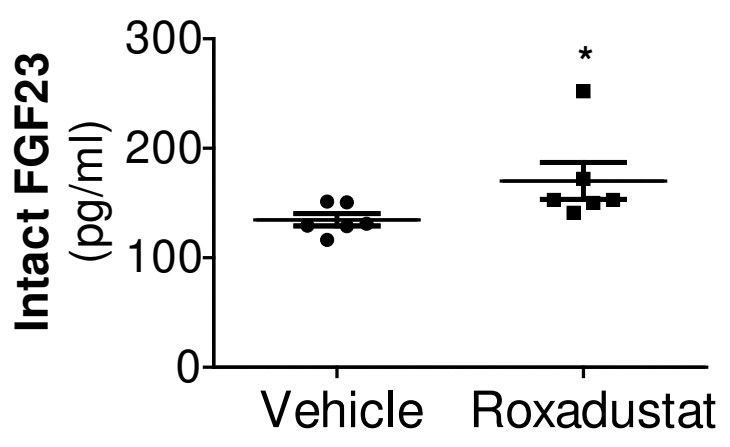


Figure 8

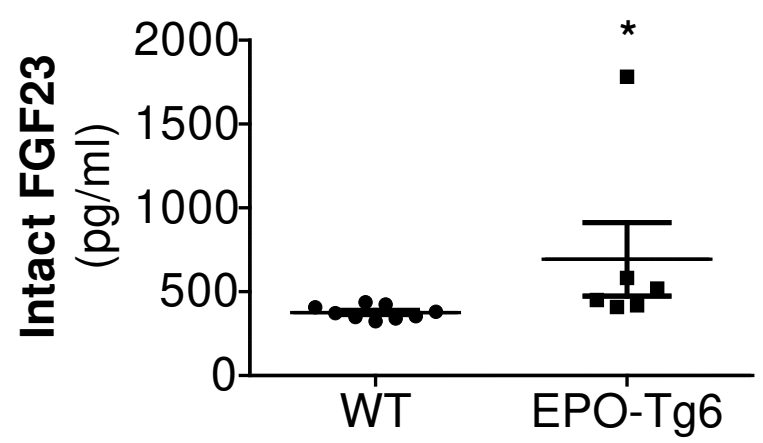


a

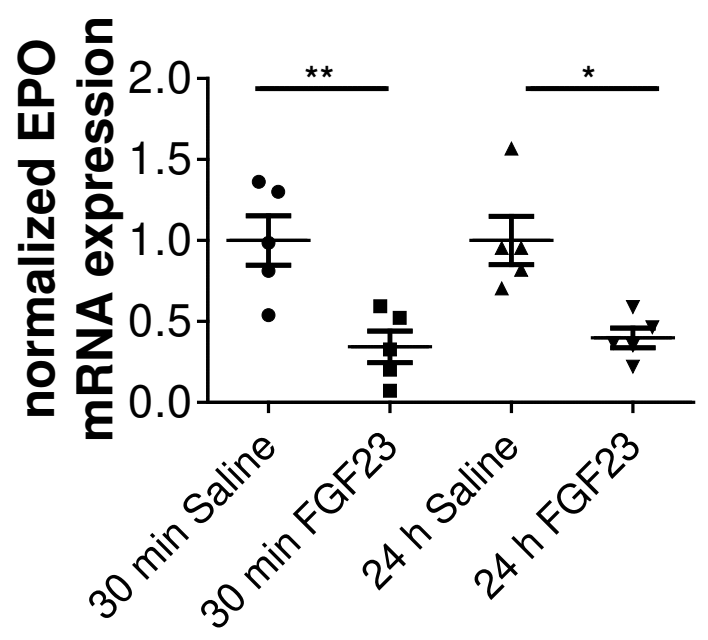

C

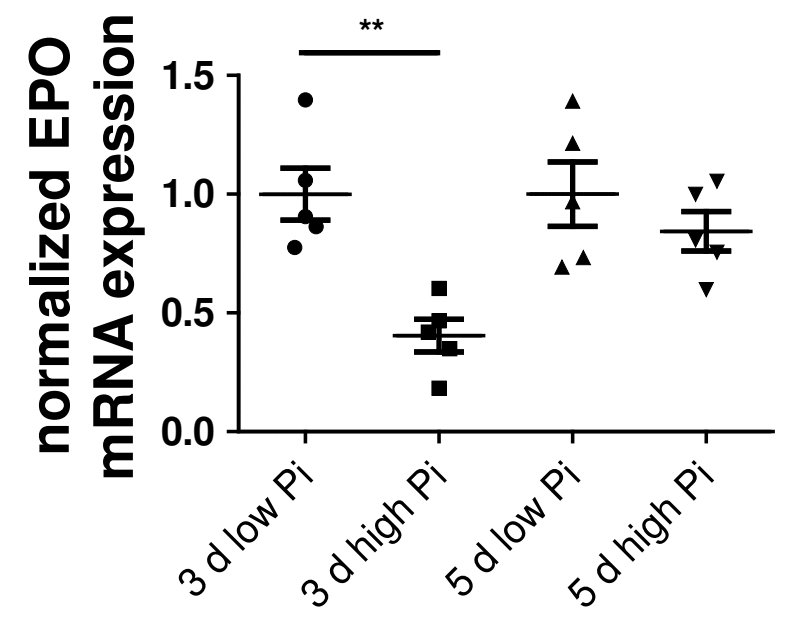

b

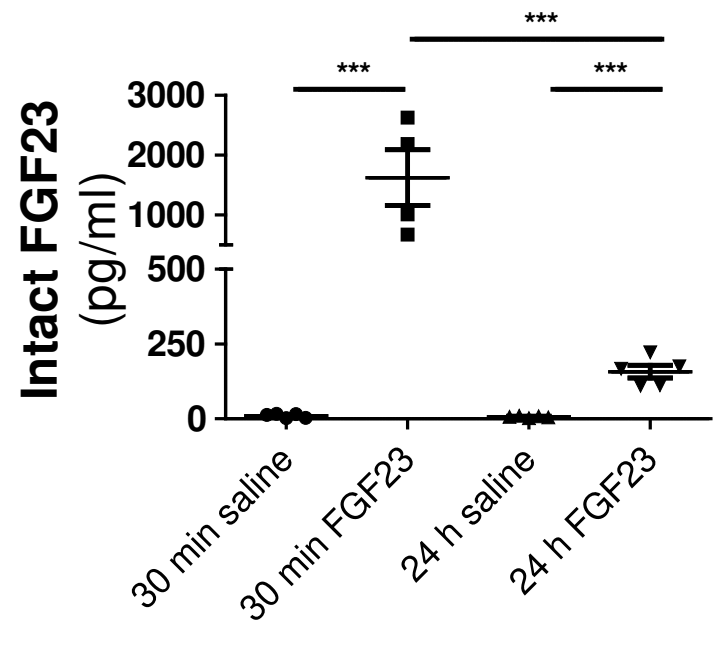

d

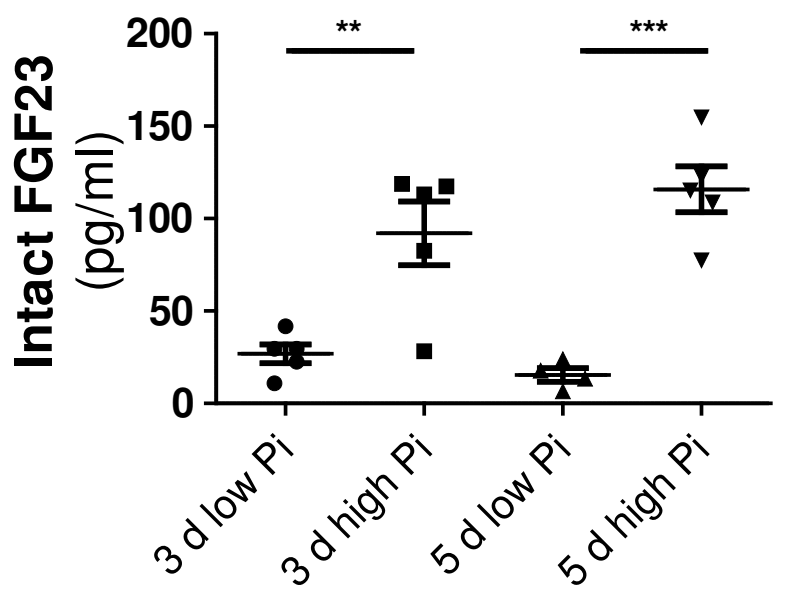




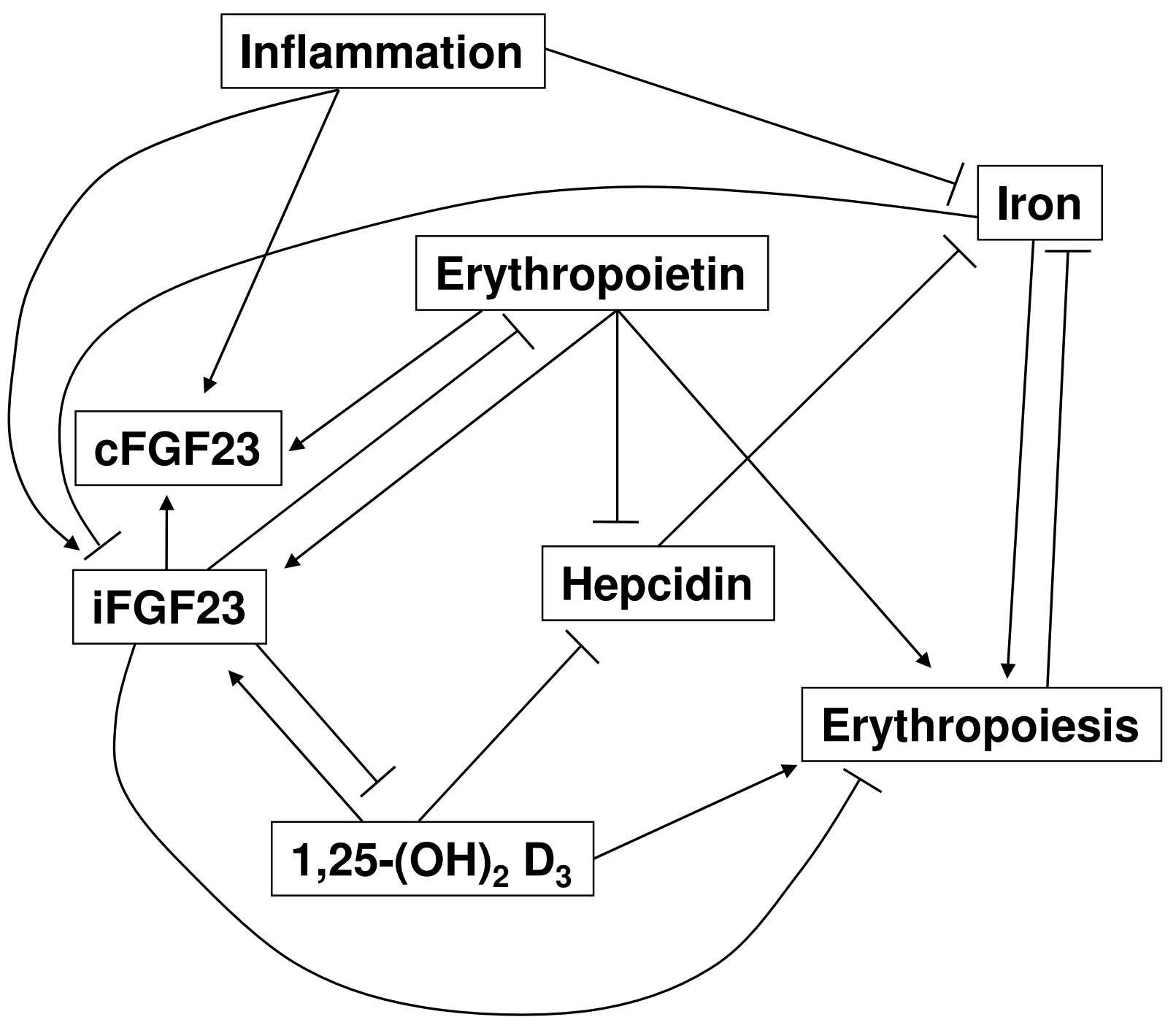

